This item was submitted to Loughborough's Research Repository by the author.

Items in Figshare are protected by copyright, with all rights reserved, unless otherwise indicated.

\title{
Appraisal of email use as a source of workplace stress: A person- environment fit approach
}

PLEASE CITE THE PUBLISHED VERSION

http://doi.org/10.17705/1jais.00531

\section{PUBLISHER}

(C) Association for Information Systems

\section{VERSION}

AM (Accepted Manuscript)

\section{PUBLISHER STATEMENT}

This work is made available according to the conditions of the Creative Commons Attribution-NonCommercialNoDerivatives 4.0 International (CC BY-NC-ND 4.0) licence. Full details of this licence are available at: https://creativecommons.org/licenses/by-nc-nd/4.0/

\section{LICENCE}

CC BY-NC-ND 4.0

\section{REPOSITORY RECORD}

Stacey, Patrick, Jean-Francois Stich, Monideepa Tarafdar, and Cary L. Cooper. 2019. "Appraisal of Email Use as a Source of Workplace Stress: A Person-environment Fit Approach”. Loughborough University. https://hdl.handle.net/2134/32714. 


\title{
APPRAISAL OF EMAIL USE AS A SOURCE OF WORKPLACE \\ STRESS: A PERSON-ENVIRONMENT FIT APPROACH ${ }^{1}$
}

\begin{abstract}
The paper develops and tests theory that explains under what conditions the extent of email use is appraised as a stressor. Integrating concepts from information acquisition and person environment fit theories, we hypothesize that individuals appraise their extent of email use as stressful based on the mismatch between their current and desired extents of email use. We define such match as email fit and mismatch as email misfit. We first develop a conceptual framework that associates email misfit with the individual's experience of three key workplace stressors - work relationship stressor, job control stressor and job conditions stressor. We then develop hypotheses framing the relationship between email fit and misfit, and these stressors. We test our hypotheses by applying quadratic polynomial regressions and surface-response analysis, to survey data obtained from 118 working individuals. The paper makes three theoretical contributions. Firstly, in reporting a theoretical and empirical construction of email fit and misfit and their relationship to workplace stressors, it shows that, email misfit is appraised as stress-creating. That is, both too much and too little email compared to what the individual desires, are associated with stressors. In doing so and secondly, it shows that IT use (in this case, email) is appraised as stressful both when it exceeds (i.e., associated with overload) and fails to meet (i.e., associated with underload), the user's expectation and preference. Thirdly, it suggests the person environment approach as a theoretically novel way to conceptualize the cognitive appraisal and judgement associated with information under - and over - acquisition, and shows workplace stressors as potentially new effects associated with them.
\end{abstract}

Keywords: email use excess, email use deficit, email overload, email underload, workplace stress, technostress, appraisal, information acquisition, person-environment fit, responsesurface methodology, polynomial regression.

\footnotetext{
1 The authors thank the Senior Editor Prof. Glenn J. Browne for his keen guidance and three anonymous reviewers for comments and suggestions - all of which helped us to significantly improve the paper
} 


\section{Introduction}

Email is the most widely used and enduring medium of electronic communication in organizations. Multi-year surveys (in 2002, 2008, and 2014) indicate that on average, about $61 \%$ of employees consider email to be very important to their jobs (Pew Research Center, 2014). Even as email has become the backbone of electronic organizational communication, studies indicate that the extent of email use has impacts beyond just communication, and particularly on workplace stressors (e.g., Barber \& Santuzzi, 2015; Barley, Meyerson, \& Grodal, 2011; Mano \& Mesch, 2010).

Research on consequences of email use on employees reports contradictory results. While some studies suggest that a higher extent of email use is associated with higher levels of workplace stress-related effects (e.g., Barley et al., 2011), others show it is associated with positive outcomes such as improved supervisor-subordinate relationships (de la Rupelle, Fray, \& Kalika, 2014) and greater work effectiveness (Mano \& Mesch, 2010). Interestingly, not having enough email can also have adverse consequences such as increased uncertainty due to lack of information (Brown, Duck, \& Jimmieson, 2014) or perceived lack of social support (Mikal, Rice, Abeyta, \& DeVilbiss, 2013). These examples suggest that the effect of email use on workplace stress is subjectively perceived and appraised by the individual. The most common manifestation of this subjectivity is 'email overload' (Whittaker \& Sidner, 1996), which is the individual's perception of being inundated with emails that he or she considers too numerous or frequent or difficult to handle (Dabbish \& Kraut, 2006). Thus, subjectivity is involved in individuals' appraisals of the demands from email load (KarrWisniewski \& Lu, 2010).

In view of the above, we discern two key gaps in the literature. The first is that studies do not explain how such appraisal takes place. The second is that they focus primarily on the effects of too much email use (overload) and not on those of too little or inadequate email use. Complementing these theoretical gaps, organizations are faced with a lack of practical solutions to deal with the problem of email load faced by employees. They continue to use 
one-size-fits-all solutions to deal with email overload; for instance, Volkswagen's after-hours lockdown of email servers for specific employees (Williams, 2011). Such solutions do not consider individuals' preferences regarding the use of email. The objective of this paper is to address these knowledge gaps by examining the research question - Under what conditions is the extent of email use appraised as a source of workplace stress?

To tackle the research question, we draw on and integrate two theoretical lenses. First, we draw from studies on information acquisition (e.g., Browne \& Pitts, 2004; Connolly \& Thorn, 1987), to argue why both over and under acquisition of information can potentially occur in organizational information processing, and lead to negative outcomes. Second, drawing on the person-environment fit theory (Edwards, Cable, Williamson, Lambert, \& Shipp, 2006), we define 'email fit' as the condition when the individual's extent of email use equals their desired extent of email use, and 'email misfit' as that when the individual's extent of email use is greater or less than their desired extent. We hypothesize that in comparison to the condition of email fit, that of email misfit is associated with higher levels of three key workplace stressors (Faragher, Cooper, \& Cartwright, 2004) - work relationships stressor, job control stressor and job condition stressor. We test our hypotheses by applying quadratic polynomial regressions and surface-response methodology (Klein, Jiang, \& Cheney, 2009) to survey data obtained from 118 working individuals in the US.

The paper effects a conceptual integration between the information acquisition (Connolly \& Gilani, 1982; Connolly \& Thorn, 1987) and person environment fit (Edwards, 1996; French, Caplan, \& Van Harrison, 1982) literatures by suggesting the former as an explanation for email fit and misfit, and the latter as a new theoretical and empirical framing to understand the effects of over and under acquisition of information. It introduces the concepts of email fit and misfit to the literature on stress from email use, which explain why individuals subjectively appraise and judge their extent of email use as being a stress creator or not. It further introduces two concepts, both of which are associated with high levels of workplace stressors - that of 'email use excess' and 'email use deficit'. These conditions respectively 
describe situations under which individuals perceive their extent of email use to be more and less than what they desire it to be. It thus theoretically broadens the literature which has so far considered only email 'overload' to incorporate the fuller spectrum of email use excess and email use deficit. Further, it contributes to the broader literature on stress from IT use (technostress) by considering the notion that not only too much but also too little demand from IT use, compared to what the individual desires, is a potential cause of stress.

In the next section, we present our literature review and theoretical framing. In section 3 , we develop our theoretical model of why individuals appraise their extent of email use to be a stress creator. We frame our research hypotheses in Section 4. Section 5 describes the methods adopted in this study - the data, its analysis and results - along with its limitations. Section 6 discusses the paper's contributions to theory and practice.

\section{Literature Review and Theoretical Framing}

We first review prior research on workplace email use and articulate research gaps in current understanding of the stress creating effects of email. We then present perspectives from the information acquisition literature to understand how individuals cognitively judge over- and under-acquisition of information, as a theoretical framing to explain why email use excess and email use deficit may be problematic. Finally, we draw from person-environment fit concepts from the organizational stress literature to explain how the concepts of fit and misfit can be used to frame over- and under-acquisition of information. In so doing, we explain the appraisal of email use excess and email use deficit as stress creators.

\subsection{Workplace stressors associated with email use}

Studies examining individuals' email load focus on a number of aspects such as the amount of email being sent, read and received (e.g., Mano \& Mesch, 2010), the time spent dealing with email (Barley et al., 2011; Sumecki et al., 2011), the frequency and intensity at which emails arrive and interrupt (Wajcman \& Rose, 2011; Whittaker \& Sidner, 1996), and the effort spent in interpreting email content (Friedman \& Currall, 2003). These aspects taken together 
are regarded as being key contributors to the individual's overall email load. They signify the extent of the individual's email use (Byron, 2008). The focus in the literature has been primarily on 'too much' email or email 'overload', defined as email users' perceptions that their email use is out of control because they have to deal with a greater extent of email use than they can process effectively (Dabbish \& Kraut, 2006). A technology feature contributing to this is the ease with which one to many communication can occur in email applications, as demonstrated by the extensive use of the 'carbon copy' (cc) function (Barron \& Yechiam, 2002). Taken together, these amplify the extent to which email is used. The literature on workplace stress from the use of IT (technostress) provides a similar focus wherein technology attributes such as usefulness and reliability (Ayyagari, Grover, \& Purvis, 2011), and stress creating conditions such as techno-overload (e.g., Tarafdar, Qiang Tu, RaguNathan, \& Ragu-Nathan, 2007) are examined in the qualitative characterization of demanding too much from the individual.

Email overload has been associated with increased workplace stressors such as unfavorable job conditions (Barley et al., 2011; Reinke \& Chamorro-Premuzic, 2014), work overload (Barley et al., 2011), and reduced job control (Sumecki et al., 2011). It can lead to the individual experiencing higher workload in the form of more time spent handling email and a longer and faster paced workday (Barley et al., 2011). More time spent handling email has been associated with high levels of work stress (Mano \& Mesch, 2010), emotional exhaustion, burnout (Barber \& Santuzzi, 2015; Brown et al., 2014; Reinke \& ChamorroPremuzic, 2014), health-related absenteeism, and poor sleep quality (Barber \& Santuzzi, 2015).

Certain qualitative aspects of email use can also be perceived as workplace stress creators. Email content can be disturbing or demanding. Aggressive email content (i.e., email flaming) can lead to conflict escalation and poor work relationships (Baruch, 2005; Friedman \& Currall, 2003). Email received from superiors (e.g., Byron, 2008) or received at a particular time (Derks, van Duin, Tims, \& Bakker, 2015) can be perceived as causing stress. However, 
these qualitative aspects depend on specific situations, and thus need to be investigated on an email-by-email basis.

\subsection{Research gaps}

The above discussion leads us to note a number of research gaps. First, the primary negative condition examined with respect to email use has to do with too much email that is overwhelming and overloading. Studies have examined email overload, using measures such as "I find dealing with my email overwhelming" (Dabbish \& Kraut, 2006, p. 434) or "I get too much email" (Hogan \& Fisher, 2006, p. 1). They look at individuals' perceptions of having 'too much' email, and characterize this condition as email overload. Studies have not considered the condition of individuals having 'not enough' email and why this may be stressful.

Second, while studies acknowledge that extent of email use is associated with workplace stressors, they do not explain why that may be so. From the literature (e.g., Lazarus, 1990), we know that individuals judge the presence of stressors by subjectively appraising whether or not a condition in the environment is stressful. This process, known as 'appraisal', is defined as one by which an environmental condition is interpreted by the individual to be a stress creator (Cooper, Dewe, \& O'Driscoll, 2001; McGrath, 1976). Applying this to the case of email, individuals subjectively appraise the extent of email use as a stress creator. This being so, it is important to consider the individuals' preferences in their email use. The same extent of email use may be appraised differently by individuals, depending on their preferences (Karr-Wisniewski \& Lu, 2010). Although there is recognition of this in the literature, there is no explanation of how appraisal takes place. Theoretical articulation of appraisal - lacking in this literature - is thus needed for understanding why individuals experience workplace stressors because of their email use.

Third, in the absence of an understanding of the conditions under which email is appraised as stressful, the measurements of email overload and stressors due to email use have often 
been mixed together. For instance, email has been assessed as being stressful by using items such as "I find dealing with the amount of e-mails I receive stressful" (Brown et al., 2014, p. 335) or "emails are a cause of personal stress" (Sumecki et al., 2011, p. 409). Such measurements conflate the extent of email use with the perception of stress in the same measurement item, without getting at why or when email use is appraised as stressful.

These research gaps point to the need to develop a conceptual model to explain under what conditions the extent of email use is appraised as being a stress creator, in order to understand the relationships between email use and workplace stressors. To do this, we next turn to concepts from information acquisition to explain why individuals could face the conditions of over and under acquisition of information.

\subsection{Information acquisition}

Individuals heuristically judge the information they need for organizational tasks. As such they find it difficult to evaluate the exact amount of information required. Studies show two types of information acquisition conditions that individuals are subject to - over acquisition and under acquisition (Ackoff, 1967; Connolly \& Gilani, 1982; Connolly \& Thorn, 1987). The former involves gathering more information than is needed, causing excess information. The latter is a condition of potential deficiency in acquired information.

Individuals try to assess information acquired through the application of stopping rules (Browne \& Pitts, 2004). These rules focus on the completeness or sufficiency of information obtained for a particular decision situation. There are two kinds of stopping rules based on 'absolute standard' and 'difference' respectively (Browne \& Pitts, 2004). In the first, the individual continues to gather information until an absolute level of information is attained. This level could be based on a predetermined information threshold (Gettys \& Fisher, 1979) or a mental list of criteria of needed information (Schank \& Abelson, 1977). When the information acquired crosses the threshold in term of the specified conditions, the individual stops further acquisition. That second, that is, difference stopping rules are most commonly 
based on the difference between a 'desired' and a 'current' level of information, or of representational stability of the problem being tackled that the information enables (Browne \& Pitts, 2004). The individual has a mental representation of how much is desired, and cognitively judges when the incoming information is not sufficiently different in that it fails to provide new understanding, as a criterion for stopping (Gettys \& Fisher, 1979). Such stopping rules have been examined in the context of information systems development, financial investment, and online search (e.g. Browne and Pitts 2004, Pennington \& Kelton, 2016).

Difference stopping rules are applicable when the decision making situation - involves a general rather than a specific task; does not require specialized expertise or experience; is characterized by low likelihood of the individual having an idea of how much absolute information they would need; and is not necessarily well defined (e.g., Browne \& Pitts, 2004). These conditions generally apply to email use because - email use is a general purpose information processing and communication activity rather than a specific technical task (Ducheneaut \& Watts, 2005); it is not possible for individuals to identify how many emails they need; email use does not entail specialized expertise; email use is a general activity occurring throughout the workday (Renaud, Ramsay, \& Hair, 2006); and there are no universally defined procedures for using email.

Through a similar logic in Prospect Theory, Kahneman and Tversky (1979) state that individuals are better able to subjectively assess the significance of a difference in an attribute rather than its absolute value. That is, they find gains and losses (i.e., changes) in the attribute more salient than its actual value. This is because the individual's perceptual apparatus is attuned to the evaluation of differences rather than of that of absolute magnitudes. In the social sciences, this principle has been found to be applicable to a large variety of attributes, including prestige and wealth (Kahneman \& Tversky, 1979). The carriers of salience are thus changes in the value of the attribute. This notion is compatible with principles of perception and judgment, wherein the individual compares the information 
gathered to a subjective reference point for the chosen attribute (Pennington \& Kelton, 2016). 'Congruence' (Chandra \& Krovi, 1999) occurs when the information gathered 'fits' the individual's information processing need. A lack of congruence or 'fit' negatively affects decision outcomes (Pennington \& Kelton, 2016). We note that a lack of fit can happen both when the information needed is greater or less than the actual information. That is, both over and under acquisition of information can lead to lack of fit. We further observe that individuals rely on their judgment and cognitive appraisal regarding whether or not they have the information they need and would not further benefit from further information. Stopping rules are thus based on judgement and cognitive appraisal.

The assessment of difference can, in principle, be based on a single or multiple criteria. However, in reality, individuals find it difficult to simultaneously assess the differential validity of multiple criteria because information overload tests the limits of cognition (Jennings, Amabile, \& Ross, 1982). Thus, for the sake of simplicity and to avoid having to cope with too much information, individuals may implicitly use a single or overall criterion as a satisficing strategy (Browne, Pitts, \& Wetherbe, 2007).

To recapitulate then, in this subsection we explained that both under and over acquisition of information signify a lack of fit and may be problematic, and that stopping rules provide a conceptual framing for judging when an individual in a given decision situation could stop gathering more information. The person environment fit approach provides a comparative judgement framework that subjectively examines information about what the person wants and what the environment provides and analytically examines their difference (Edwards et al., 2006; Kristof-Brown, Zimmerman, \& Johnson, 2005). It could thus provide a conceptual framing for understanding how over and under acquisition, or lack of fit, is appraised by the individual. We therefore next turn to the person environment fit theory. 


\subsection{Person-environment fit approach to understanding appraisal}

Appraisal is the process by which an environmental condition is interpreted by the individual as a stress creator (Cooper et al., 2001; McGrath, 1976)2. We noted in Section 2.2, the lack of understanding of how individuals appraise their extent of email use as a stress creator. The person-environment fit theory (Edwards, 1996; French et al., 1982) provides a conceptual and methodological framework to understand how individuals appraise an environmental attribute to be a stress creator or stressor, depending on the extent to which it 'fits' their desired levels of the attribute. It suggests that in order to do this, individuals cognitively appraise the extent to which they perceive the attribute to be present, and the extent to which they would like it to be present (Van Harrison, 1978). This approach is conceptually related to the matter of both stress from email use (because it provides a framework to appraise the extent of email use as a stressor) and to information acquisition (because it provides a framework to cognitively judge the extent of information the individual has acquired and qualify it as over or under acquisition).

Supplies (S) are described as the extent to which the particular attribute is currently perceived to be present in the environment. Values (V) represent the extent to which the attribute is desired by the person (Edwards, 1996). The difference (match) between the two is classified as misfit (fit). The person judges the current and desired extents of the attribute (Edwards, 1996), and the result of their comparison is defined as a fit or misfit. When the current and desired extents of the attribute diverge, a Supplies-Values misfit (S-V misfit) exists. The greater this divergence, the more the S-V misfit. In general, the greater the S-V misfit, the greater the experienced level of a particular stressor perceived by the individual

\footnotetext{
2 Appraisal occurs at two points of the stress process. Primary appraisal occurs when individuals perceive environmental demands as stress creating. Secondary appraisal is activated after the individual has appraised the presence of a stressor and evaluates possible coping behaviors. The objective of this study is to understand under what conditions email use is appraised as stress creating. The focus is thus on primary appraisal. Person-environment fit theory is particularly appropriate for studying primary appraisal (Cooper, Dewe, \& O'Driscoll, 2001; Lazarus \& Folkman, 1984). For the sake of readability, we refer to it as simply 'appraisal'.
} 
(Kristof-Brown et al., 2005). This is true both when supplies exceed values and whey they fall short of values. When the supply exceeds the value, the individual experiences an 'excess' condition in which the level of the attribute goes 'over' what he or she wants. When supply falls short of values, the individual experiences a 'deficit' condition in which the level of the attribute is 'under' what he or she wants. Key works in stress (e.g., Lazarus, 1990; McGrath, 1976; Selye, 1956) conceptualize the relationship between the level of misfit and the level of the stressor as a non-linear one.

Conceptually integrating the information acquisition and person environment fit perspectives enables us to suggest that over and under acquisition of information can be appraised as being stressful. It helps us address the inadequacies in the current literature on stresscreating attributes of email use, which does not take into account that email use can be stressful, both when it is in excess and in deficit of what the person would like it to be. In existing studies, measurement items such as "I get too much email" (Hogan \& Fisher, 2006, p. 1) do not separate out between the extent to which the individual uses email (supplies) and the extent to which the individual would like to use email (values). This presents the problem that only one side of the relationship (i.e., email overload) is considered by looking at 'too much email', thus overlooking the condition of 'not enough email' (i.e., potential email underload). Such measures are thus one-sided (Edwards et al., 2006) and do not provide a complete assessment of misfit from both sides.

For studies on technostress, we note two deficiencies. First, there is no empirical evidence of a supplies-values misfit or if that is actually associated with workplace stressors. Ayyagari et al. (2011) provide a conceptual deliberation of how IT characteristics such as complexity or pace of change, can be potentially associated with misfit, but do not consider use of an IT application. Second, studies have developed indicators of stress creating conditions that address the condition of 'too much'. Technology-related overload is measured by indicators such as 'I am forced by the technology to do more work than I can handle' (Tarafdar et al., 2007). Technology attributes are measured with indicators such as 'I feel that there are 
frequent changes in the features of ICTs' (Ayyagari et al., 2011). These indicators are not able to empirically investigate the relationship between fit or misfit and stress creating conditions due to IT. Neither do they get at why individuals appraise stressors due to IT.

\section{Conceptual model: how email use is appraised as a stressor}

The information acquisition literature covered in Section 2.3 considers both over acquisition and under acquisition of information as potentially problematic. The person-environment fit literature in Section 2.4 regards that individuals cognitively appraise the environment by judging the levels of supplies (what they currently have) and values (what they would like to have) of attributes in the environment. When the two levels do not match, a condition of misfit occurs which can to lead to the perception of a high level of stressors. The personenvironment approach thus explains that misfit may be a way to theoretically qualify over and under acquisition of information. Integrating the two perspectives, we consider email use excess (email use deficit) as a situation of information over (under) acquisition. We further consider both situations as one of 'misfit'. We next develop a conceptual model where we draw from this framing to explain the relationships between the extent of email used by the individual and the level of work stressors perceived by him or her.

We consider the extent ${ }^{3}$ of email the individual currently uses as an indicator of email load (e.g., Dabbish \& Kraut, 2006; Soucek \& Moser, 2010; Sumecki et al., 2011). As shown in Figure 1, we define email supplies (S) as the individual's subjectively assessed current extent of email use, and email values $(V)$ as the extent to which the individual desires or would like his or her email use to be. For individuals to experience email fit, they should use email to the extent they want to. Otherwise, they would experience email misfit when their

\footnotetext{
${ }^{3}$ As explained in Section 2.1, the extent of email use is regarded as an overall assessment of the individual's email load, including different aspects such as volume, frequency, intensity etc., all of which contribute to the level of the individual's email use. As further explained from information acquisition concepts in Section 2.3, individuals consider simple attributes when assessing adequacy of information for work tasks, so as not to experience cognitive overload. Thus it is possible to suggest that the individual considers a simplified criterion signifying the overall extent of email use, when assessing email load.
} 
extent of email use is in excess (i.e., email use excess - right side of Figure 1 where $\mathbf{S}$ exceeds $\mathrm{V}$ ) or in deficit (i.e., email use deficit - left side of Figure 1 where $S$ is less than V). The more the current extent of email use deviates from the desired (i.e., misfit on both sides of the $\mathrm{S}=\mathrm{V}$ position in Figure 1 ), the higher the level of stressors appraised by the individual.



We examine the impact of email fit and email misfit on the perceived levels of three workplace stressors, namely work relationships stressor, job control stressor and job conditions stressor (Cooper et al., 2001). We selected these workplace stressors because they have the potential to be affected by the extent of email use and because they have been highlighted as strong predictors of long standing workplace well-being issues such as burnout, depression and reduced mental health (Bond \& Bunce, 2003; Faragher, Cass, \& Cooper, 2005; Sutherland \& Cooper, 2000). 'Work relationships stressor' is defined as conditions of poor, unsupportive or damaging relationships with colleagues experienced by 
the individual (Leiter \& Maslach, 1988; McGrath, 1970). The importance of this stressor is highlighted because "having to live and work with others can be one of the most stressful aspects of life" (Sutherland \& Cooper, 2000, p. 98). The job control stressor is defined as a lack of control or influence that the individual perceives over his or her job (Karasek, 1979). This has been an important stressor because it can lead to low mental health, job satisfaction and job performance (Bond \& Bunce, 2003). The use of an individual's email is dependent on its use by one's colleagues (Renaud et al., 2006), and is especially subject to potential control by supervisors. Thus, both the work relationships stressor and the job control stressor can potentially be associated with email use. The job conditions stressor describes overall difficult working conditions perceived by the individual. This stressor is important because unpleasant working conditions create an undesirable working climate (Faragher et al., 2005). It is salient with regard to email use in multiple ways, such as through the lengthening of the workday due to email load (Barley et al., 2011) or through the potential of email use to convey harassing and abusive workplace behaviors (Baruch, 2005). For each stressor, it is theorized that email misfit ('too much' and 'too little' email use) will be associated with higher levels of the stressor. Conversely, email fit ('enough' email use) will be associated with lower levels of the stressors. Individuals may experience email fit with any level of email supplies.

Before proceeding to the hypotheses, it is important to note three things regarding the nature of email use excess, email use deficit, email fit and email misfit. First, excess and deficit occur on two sides of the same attribute - from the information acquisition view, as well as from the organizational stress and person-environment fit literatures. From the information acquisition view, people either acquire more information or less information, but their assessments of 'more' or 'less' are commensurate along the same attribute. The organizational stress literature shows that individuals evaluate supplies and values by making self-assessments of the desired and current levels of the same attribute for which fit and misfit are studied (e.g., Caplan, 1987; Van Harrison, 1978), in this case, extent of email 
use. The person-environment fit perspective makes the same argument of excess and deficit conditions being evaluated using the same attribute. Thus, attributes for which fit and misfit are measured have been treated as commensurate in these literatures. We extend the same logic to extent of email use. Second, email load is subjectively perceived. The stress literature emphasizes that attributes in the environment are subjectively appraised by individuals in order to be perceived as stressors (Lazarus, 1990). Thus, although objective email related data such as the number of emails received as counted by servers can be measured (e.g., Jackson, Dawson, \& Wilson, 2003), such data is unlikely to influence fit and misfit. Third, as we noted in Section 2.2, the literature uses indicators that ask respondents to report their perceived email overload. Known as molecular measures, they suffer from the drawback that individuals may confound the evaluation of the condition (i.e., email fit or misfit) with the attribute of comparison (i.e., extent of email use) ${ }^{4}$. In this study, we adopt an 'atomistic' approach that consists of appraising the environment by subjectively assessing email supplies and email values separately. Each is a cognitively assessed judgment, respectively of the extent of email the individual currently has and wants. We then compare them analytically to assess fit and misfit. This approach makes it possible to separately assess the excess and deficit conditions of email use (i.e., email misfit). It also enables the assessment of email fit (Edwards et al., 2006).

\section{Research hypotheses}

Based on the preceding background, we develop two sets of hypotheses as follows. The first set of hypotheses examines the relationship between email misfit and the three workplace stressors - work relationship stressor, job control stressor and job conditions stressor. The second set investigates if the level of the three stressors experienced by the individual at email fit increases as the extent of email use increases. Table 1 describes the hypotheses.

\footnotetext{
4 For instance, the items "I use email more than I want" and "I want to use email less than I do" are both measures of email misfit (email overload). However, the former condition may be perceived as being less preferable than the latter because of the way the items are worded.
} 
Table 1: Summary of Definitions and Hypotheses

\begin{tabular}{|c|c|c|}
\hline & Email misfit & Email fit \\
\hline & $\begin{array}{l}\text { Misfit occurs when the current } \\
\text { extent of email use deviates from } \\
\text { the desired extent. This misfit can } \\
\text { occur in any direction (e.g., "too } \\
\text { little" or "too much" email use) } \\
\text { (Edwards, 1996). }\end{array}$ & $\begin{array}{l}\text { Fit occurs when the current extent } \\
\text { of email use equals the desired } \\
\text { extent. (Edwards, 1996). }\end{array}$ \\
\hline Definition & Hypotheses & Hypotheses \\
\hline $\begin{array}{l}\text { Work relationships } \\
\text { stressor: Stress creating } \\
\text { conditions due to poor, } \\
\text { damaging, absent or } \\
\text { unsupportive relationships } \\
\text { with coworkers (Leiter \& } \\
\text { Maslach, 1988; McGrath, } \\
\text { 1970). }\end{array}$ & $\begin{array}{l}\text { H1a: The higher individuals } \\
\text { experience email misfit (i.e., when } \\
\text { the current extent of email use } \\
\text { deviates from the desired extent), } \\
\text { the higher they perceive the work } \\
\text { relationships stressor. }\end{array}$ & $\begin{array}{l}\text { H2a: The level of work } \\
\text { relationships stressor will not } \\
\text { increase when the extent of email } \\
\text { use increases as long as email fit } \\
\text { is maintained (i.e., when the } \\
\text { current extent of email use equals } \\
\text { the desired extent). }\end{array}$ \\
\hline $\begin{array}{l}\text { Job control stressor: } \\
\text { Stress creating conditions } \\
\text { due to lack of control over or } \\
\text { influence in the job } \\
\text { (Karasek, 1979). }\end{array}$ & $\begin{array}{l}\text { H1b: The higher individuals } \\
\text { experience email misfit (i.e., when } \\
\text { the current extent of email use } \\
\text { deviates from the desired extent), } \\
\text { the higher they perceive the job } \\
\text { control stressor. }\end{array}$ & $\begin{array}{l}\text { H2b: The level of job control } \\
\text { stressor will not increase when the } \\
\text { extent of email use increases as } \\
\text { long as email fit is maintained (i.e., } \\
\text { when the current extent of email } \\
\text { use equals the desired extent). }\end{array}$ \\
\hline $\begin{array}{l}\text { Job conditions stressor: } \\
\text { Stress creating conditions } \\
\text { due to overall difficult } \\
\text { working conditions } \\
\text { (Faragher et al., 2005). }\end{array}$ & $\begin{array}{l}\text { H1c: The higher individuals } \\
\text { experience email misfit (i.e., when } \\
\text { the current extent of email use } \\
\text { deviates from the desired extent), } \\
\text { the higher they perceive the job } \\
\text { conditions stressor. }\end{array}$ & $\begin{array}{l}\text { H2c: The level of job conditions } \\
\text { stressor will not increase when the } \\
\text { extent of email use increases as } \\
\text { long as email fit is maintained (i.e., } \\
\text { when the current extent of email } \\
\text { use equals the desired extent). }\end{array}$ \\
\hline
\end{tabular}

\subsection{Relationship between email misfit and the three work stressors - work}

\section{relationships stressor, job conditions stressor and job control stressor}

From the information acquisition theory, we know that both over and under acquisition of information can have negative impacts for the individual. From the point of view of fit-based appraisal mechanisms from the stress literature, such misfits can lead to the perception of stressors. We draw from this logic to frame this set of research hypotheses. Email misfit occurs when the current extent of email use diverges from the desired extent. 
Email misfit can cause individuals to experience high levels of work relationships stressors in a number of ways. First if the extent of email use is greater than the desired extent, they may feel irritated or annoyed with colleagues for sending too many emails and/or for having to respond to them (Derks \& Bakker, 2010). They may also feel that excessive email use comes at the cost of face-to-face work communication and the accompanying immediacy (Golden \& Veiga, 2005), or that it places undue demands on their time (Barley et al., 2011). Perceiving one's email use to be too frequent may also lead to information overload or increased negative affect about email. This can increase risks of perceiving email content unduly negatively (Byron, 2008), thereby creating or escalating conflicts, and resulting in poorer work relationships (Friedman \& Currall, 2003). When the current extent of email use is less than the desired extent, individuals may feel that they are not getting enough social support (Mikal et al., 2013), especially when emails are left unanswered or have low frequency. There is also increased opportunity for misunderstandings because of lack of adequate information (Brown et al., 2014; de la Rupelle et al., 2014), leading to poorer work relationships (Friedman \& Currall, 2003). A perceived paucity of email might also lead to increased perceptions of isolation, especially in virtual teams or teleworking situations which rely heavily on regular email for socialization (Golden \& Veiga, 2005). Finally, lower than desired extent of email use might cause the individual to feel that work colleagues are not pulling their weight (Chidambaram \& Tung, 2005) and lead to soured workplace relationships. In general therefore, as email communication involves several participants, email misfit may be associated with individuals perceiving that relationships with workplace colleagues are poor.

In situations of fit however, using email to the extent that it is desired may activate stopping rules with regard to the need for more email and could lead to perceptions of adequate social support and satisfactory work communication and to an overall perception that their work relationships are not stress creators. We hypothesize the following: 
H1a: The higher individuals experience email misfit (i.e., when the current extent of email use deviates from the desired extent), the higher they perceive the work relationships stressor.

Email misfit can be linked to job control stressor in the following ways. In the context of email use after working hours for example, using email more than desired might, on the face of it, seem like a good idea to improve flexibility in work-home life and information access, but may ultimately result in lowered autonomy and job control as individuals find it more difficult to disengage from work (Cavazotte, Heloisa Lemos, \& Villadsen, 2014). One's own email use is partly the result of others' decisions to send email (Waller \& Ragsdell, 2012). Using email more than desired may lead to the perception that others are in control of one's email use (Renaud et al., 2006; Sumecki et al., 2011), as a result of which one's own email is excessive or too frequent (Dabbish \& Kraut, 2006). Increased difficulties to manage use of email that is higher than desired can thus lead to a higher appraisal of the job control stressor. On the other hand, when using email less than desired, individuals might feel left out of important email threads and out of the loop (Hemp 2009) and might not have access to information necessary to their jobs (Mazmanian, Orlikowski, \& Yates, 2005). These sorts of conditions may lead to a perception of lower job control.

If individuals judge their current email use to be what they want, they may feel that they have access to the information they want, and are in control of their work communication (Mano \& Mesch, 2010; Mazmanian et al., 2005; Sumecki et al., 2011). They may feel that they are able to use email to sufficiently have their say in matters and decisions important to their jobs such as their performance targets. They are thus likely to experience greater control over key aspects of their jobs, and thus lower levels of the job control stressor. They would not look for greater extent of email use, implicitly the application of stopping rules. We thus hypothesize the following: 
H1b: The higher individuals experience email misfit (i.e., when the current extent of email use deviates from the desired extent), the higher they perceive the job control stressor.

If an individual uses email more than what he or she desires, he or she might perceive greater workload in managing it. Techno-overload which denotes excessive work in managing the use of technology, has been shown to be an aspect of technostress creating conditions (Tarafdar et al., 2007). Similarly, excessive email use leads to feelings of email overload (e.g., Brown et al., 2014; Dabbish \& Kraut, 2006) and a general lengthening of workdays (Barley et al., 2011). Email can also be a source of stressful disruptions throughout the workday and a potential source of work life conflict (Mazmanian et al., 2005; Renaud et al., 2006). If dealing with clients and customers is an inherent part of the job, too much email coming from customers or clients could increase the perceptions of not being able to cope with communication demands from key stakeholders (Barley et al., 2011). Given the surveillance potential of electronic communication, individuals using email more than what they are comfortable with may also be subject to the perception of being monitored (Smith \& Tabak, 2009). Too much email may leave the individual vulnerable because ignoring or marking as spam emails sent by coworkers may not be considered acceptable (Park, Fritz, \& Jex, 2015). All of these situations may give rise to a perception of difficult job conditions.

Findings from the information load literature suggest that individuals experiencing information deficit can be stressed by their job conditions in a large part because of frustration associated with lack of necessary information for doing their jobs (O'Reilly, 1980). In the case of email use deficit, they may feel that they do not receive sufficiently adequate or useful information for the purpose of their work (Mano \& Mesch, 2010; Mazmanian et al., 2005; Sumecki et al., 2011). Individuals may also feel that they do not have enough information to process, such that the available information is processed too quickly with respect to the time available (Schultz \& Vandenbosch, 1998). In such situations, they can become bored or find their work dull and repetitive. They may resort to compulsive and 
constant monitoring of their email inbox, often in hope of receiving useful or interesting email relevant for the task at hand (Mazmanian et al., 2005; Renaud et al., 2006). Email use deficit may thus affect the job conditions stressor by making work less interesting and enjoyable, or harder to accomplish because of a lack of necessary information.

When individuals perceive that they are using email to the desired extent, they are not subject to these above conditions. They would not experience greater workload, or a sense of being monitored, nor would they experience a paucity of important information. We thus hypothesize:

H1c: The higher individuals experience email misfit (i.e., when the current extent of email use deviates from the desired extent), the higher they perceive the job conditions stressor.

\subsection{Relationship between email fit and the three work stressors - work relationships stressor, job conditions stressor and job control stressor}

Email fit occurs when the current extent of email use is equal to the desired extent. Users do not appraise email use as a stress creator as long as the current and desired extents of email use are the same. According to Tversky \& Kahneman, (1978) a difference in the value of an attribute is the reason for a perceived change in an outcome variable, rather than the absolute level of the attribute itself. In our case, the difference is that between current and desired extent of email use. In situations of email fit, using email to the extent that is desired would imply that the individual stops looking for more email. As we argued in the previous subsection, email fit is associated with perceptions of - adequate social support and work communication (relevant to work relationships stressor), adequate access to information

needed for work and say in key aspects of the job (relevant to job control stressor), and relative absence of high workload or a sense of being monitored or potential incivility (relevant to job conditions stressor). These perceptions are likely to hold irrespective of the current extent of email use. Moreover, their level/intensity is unlikely to change, whatever the 
current extent of email use, because they depend on the deviation of the current extent of email use from the desired extent of use, rather than on the current extent of email use. Thus, when arguing from the point of view of the relationship between email fit and workrelated stressors, it is possible to suggest that as long as email fit is maintained, there will be no significant change in the perceived levels of the three workplace stressors, regardless of the value of current email use at which fit occurs. From the person-environment fit literature as well, fit can occur at any level of an environmental attribute, and the level of the outcome will be perceived to remain the same, as long as fit is maintained (e.g., Edwards \& Parry, 1993). We thus frame the following hypotheses:

H2a: The level of work relationships stressor will not increase when the extent of email use increases as long as email fit is maintained (i.e., when the current extent of email use equals the desired extent).

H2b: The level of job control stressor will not increase when the extent of email use increases as long as email fit is maintained (i.e., when the current extent of email use equals the desired extent).

H2c: The level of job conditions stressor will not increase when the extent of email use increases as long as email fit is maintained (i.e., when the current extent of email use equals the desired extent).

\section{Methods}

We used the survey method to test our research hypotheses. We collected data of the independent variables (email supplies and email values) and the dependent variables (work relationships stressor, job control stressor and job conditions stressor) from a survey of email users working full-time in organizations in the US. The data was analyzed using polynomial quadratic regression and surface response methodology to examine the relationships between email fit and misfit, and the three work stressors. We describe below the following steps: (1) Survey questionnaire development; (2) Data collection; and (3) Data analysis. 


\subsection{Survey questionnaire development}

Independent variables: email supplies and email values

We recall three things from Section 3 - one, that email use excess and email use deficit are on two sides of a continuum; two, that email load is subjectively appraised; and three, that the literature focuses on measuring email overload only. Accordingly, the measurement for supplies and values that we select for this study allow for commensurate measurement, subjectivity, and measurement of both email use excess and email use deficit, as follows. First, methodological considerations of commensurate measurement from personenvironment fit research (Klein et al., 2009) suggest the use of items that incorporate simple and comparable content and wording along the same attribute dimension ${ }^{5}$. We therefore used items that use comparable wording for the current and desired extents of email use of the individual. Second, rather than the absolute volume of email, subjective impressions of supplies and values are more important (Edwards et al., 2006). If someone believes he or she is interacting through email a great deal at work, then that may be more important than the system reported number of emails ${ }^{6}$. Third, as discussed in Section 2.1, while several aspects of email (e.g. volume, frequency/intensity, length, time spent) contribute to the individual's email load. To minimize cognitive overload associated with information acquisition (Browne et al., 2007), when considering their email load, individuals are more likely to be able to assess their overall extent of email use as a single criterion rather than multiple criteria. Fourth, single item measures are recommended when such items are easily understood and capture the measured construct, whereas multiple items would be semantically redundant (Diamantopoulos, Sarstedt, Fuchs, Wilczynski, \& Kaiser, 2012). In

\footnotetext{
${ }^{5}$ Such commensurate item indicators have been used in the organizational psychology literature to investigate fit and misfit of attributes such as workload (e.g., "How much work load do you have?" for supplies and "How much workload would you like to have?" for values) (e.g., Edwards \& Van Harrison, 1993, p. 632).

6 Research shows that individuals' perceptions of their IT use (e.g., length and count of phone calls or smartphone use) are not correlated to their system-generated use (Andrews, Ellis, Shaw, \& Piwek, 2015; Higgins, McClean, \& Conrath, 1985). Likewise, there is little correspondence between the system-generated use of email, the reported use of email, and whether that is perceived as being high or low (Andrews, Ellis, Shaw, \& Piwek, 2015; Karr-Wisniewski \& Lu, 2010; Higgins, McClean, \& Conrath, 1985).
} 
the case of email use, multiple aspects such as amount of email sent, read and received, time spent in handling email, and frequency of email, may be incorporated into a single item scale due to their high homogeneity (Dabbish \& Kraut, 2006).

Based on the above, we evaluated email supplies and email values by asking respondents to report respectively, the extents to which they (1) were interacting at work using email and (2) would like to interact at work using email. The indicator items were (1) "At work, to what extent do you interact with others using e-mail?" and (2) "At work, to what extent would you like to interact with others using e-mail?" Each item was assessed using a 7-point Likert scale ranging from " $1=$ Not at all" to "7 $=$ To a very great extent". The above discussions established the appropriateness of these measures for our study.

\section{Dependent variables: work relationships stressor, job control stressor and job condition stressor}

The three dependent variables - Work relationships stressor, Job control stressor and Job conditions stressor - were measured using psychometrically reliable scales adapted from previous studies on workplace stress (e.g., Donald et al., 2005; Faragher et al., 2004; Johnson \& Cooper, 2003). Work relationships stressor was assessed with 6 items addressing the extent to which individuals are troubled that (1) they have poor relationships at work; (2) they feel isolated; (3) they lack support; (4) they are unsure about what is expected from them; (5) their superiors are constantly criticizing their work; (6) their superiors are intimidating them. Job control stressor was assessed with 4 items measuring the extent to which individuals are troubled that they have little control over (1) their jobs, (2) their performance targets, and (3) decisions impacting their jobs; and that (4) their suggestions about their jobs are not taken into account. Job conditions stressor was assessed with 4 items that measured the extent to which individuals are troubled that (1) they find their jobs repetitive; (2) their job performance is monitored; (3) their working conditions are difficult; (4) their customers are difficult to deal with. Each item was assessed on a 6-point Likert scale from "strongly disagree" to "strongly agree", Each construct was 
computed as the average of its items, based on previous studies with these constructs (Donald et al., 2005; Faragher et al., 2004; Johnson \& Cooper, 2003) and other similar constructs in the stress literature (Lyne, Barrett, Williams, \& Coaley, 2000).

\section{Control variables}

We controlled for six variables - (1) age; (2) sex; (3) education; (4) company size; (5) industry sector of the firm in which the employees worked; and (6) hierarchical level (e.g., entry level, middle management etc.) - as typical of studies on email overload (Mano \& Mesch, 2010) and stress (Faragher et al., 2004). This set of control variables embodies a large variety in individual and organizational factors that could have a bearing on the relationships we study. Selecting these thus enabled us to take into account the possible effects of a number of individual and organizational differences.

\subsection{Data}

We collected data from a sample of individuals in the US who fulfilled the following criteria (1) working full-time; and (2) using email and not interacting exclusively face-to-face in their jobs. This sample was recruited from an online panel provided by Qualtrics. Such panels are used in research on email and computer-mediated communication because of two reasons. One, users of such applications are also internet users and can therefore be reached through online panels. Two, it is possible to secure the participation of employees of multiple organizations (Brandon, Long, Loraas, Mueller-Phillips, \& Vansant, 2014; Lowry, D'Arcy, Hammer, \& Moody, 2016). 316 participants clicked on the link received by email to take part in the study and filled out the questionnaire. Out of these (1) 13 were rejected because they were not working full-time, (2) 179 were rejected because they were only interacting face-toface at work, and (3) 6 were rejected on the basis that they answered at least four times faster than the average answering time (Lowry et al., 2016). 118 valid responses were obtained with no missing data, which represents a usable response rate of 37 percent. Our sample thus consists of 118 full-time working individuals in the US. Sample characteristics 
are shown in Table 2. They include sex, age, education, organization size, and industry of employment of the respondents.

\begin{tabular}{|c|c|c|}
\hline & Count & Percentage \\
\hline \multicolumn{3}{|l|}{ Sex } \\
\hline Male & 42 & $36 \%$ \\
\hline Female & 76 & $64 \%$ \\
\hline Total & 118 & $100 \%$ \\
\hline \multicolumn{3}{|l|}{ Industry (North American Industry Classification System - NAICS) } \\
\hline Mining, quarrying, and oil and gas extraction & 2 & $2 \%$ \\
\hline Construction & 4 & $3 \%$ \\
\hline Manufacturing & 11 & $9 \%$ \\
\hline Wholesale and retail trade & 3 & $3 \%$ \\
\hline Transportation and utilities & 5 & $4 \%$ \\
\hline $\begin{array}{l}\text { Information services (e.g., telecommunications, broadcasting, data } \\
\text { hosting etc.) }\end{array}$ & 8 & $7 \%$ \\
\hline Financial services & 15 & $13 \%$ \\
\hline Professional and business services & 23 & $20 \%$ \\
\hline Education and health services & 13 & $11 \%$ \\
\hline Leisure and hospitality & 6 & $5 \%$ \\
\hline Other services & 22 & $19 \%$ \\
\hline Public administration & 6 & $5 \%$ \\
\hline Total & 118 & $100 \%$ \\
\hline \multicolumn{3}{|l|}{ Age } \\
\hline $18-30$ years & 38 & $32 \%$ \\
\hline $31-40$ years & 28 & $24 \%$ \\
\hline $41-50$ years & 22 & $19 \%$ \\
\hline $51-60$ years & 25 & $21 \%$ \\
\hline More than 60 years & 5 & $4 \%$ \\
\hline Total & 118 & $100 \%$ \\
\hline \multicolumn{3}{|l|}{ Education } \\
\hline High school or less & 13 & $11 \%$ \\
\hline Undergraduate & 82 & $69 \%$ \\
\hline Postgraduate & 19 & $16 \%$ \\
\hline Doctorate, Law or Professional Degree & 4 & $3 \%$ \\
\hline Total & 118 & $100 \%$ \\
\hline
\end{tabular}




\begin{tabular}{|l|c|c|}
\hline $1-49$ & 15 & $13 \%$ \\
\hline $50-499$ & 27 & $23 \%$ \\
\hline $500-999$ & 18 & $15 \%$ \\
\hline $1,000-4,999$ & 25 & $21 \%$ \\
\hline 5,000 or more & 31 & $26 \%$ \\
\hline Don't know & 2 & $2 \%$ \\
\hline Total & 118 & $100 \%$ \\
\hline
\end{tabular}

To assess its representativeness, we compared our sample to the overall US population along two aspects - demographically and along general indicators of well-being. Demographically, we compared the sex and industry sector characteristics of our sample to that of the full-time working population in the US as obtained from the 2013 data of the United States Department of Labor, Bureau of Labor Statistics. We find that our sample is largely representative, by sex and sector of employment, of the working population of individuals in the US. The details are presented in Table 1 of the Appendix. Regarding indicators of well-being, we compared our sample's values of self-reported physical and psychological well-being, to that of a reference database of these parameters obtained from a business-psychology well-being research firm. The database contained values of these parameters, over the past 10 years, for 38,240 employees from 27 organizations from the US, UK and Western Europe. Physical well-being was (reversely) measured through selfreported conditions such as muscular tensions, insomnia or headaches, and psychological well-being through self-reported conditions such as irritability, mood swings or anxiety. These parameters are indicators of general/behavioral (not clinical) well-being and have been used in the stress literature as such (Faragher et al., 2004) ${ }^{7}$. There was no significant difference between the mean and standard deviation (t-values) for our sample and those of the reference database, for $p<0.05$. Specifically, for overall physical well-being, the details were $\left(\right.$ Mean $_{\text {sample }}=13.84$, Standard Deviation sample $=3.94$, Mean $_{\text {population }}=13.66$, Standard

\footnotetext{
${ }^{7}$ It may be that well-being affects the three stressors and may be empirically considered a control variable. In the stress literature however, it is widely considered as an outcome of work stressors such as the ones we studied (Danna \& Griffin, 1999; Edwards \& Van Harrison, 1993; Faragher, Cooper, \& Cartwright, 2004) and thus its theoretical nature is not that of a control variable, given the objective of our study. That said, we ran alternate models incorporating physical and psychological well-being as control variables, with no qualitative changes in the hypotheses' results. We thank one of the reviewers for suggesting this.
} 
Deviation $_{\text {population }}=4.26, \mathrm{t}=0.50$ ) and for overall psychological well-being the details were $\left(\right.$ Mean $_{\text {sample }}=21.45$, Standard Deviation sample $=7.22$, Mean $_{\text {population }}=22.56$, Standard Deviation $\left._{\text {population }}=7.32, \mathrm{t}=1.67\right)$.

These comparisons show that our sample is a good representation of the population of working individuals in the US in terms of demography and employment sector, and of employees in the US, UK and Western Europe in terms of general well-being.

We tested for the possibility of common method bias in our data, for supplies, values, and each stressor. The Harman's single-factor test for common method bias found that a single factor incorporating all three variables respectively explained, $44 \%, 42 \%$ and $30 \%$ of the variance, in the case of supplies, values, and each one of the three stressors - job control stressors, job relationships stressor and job conditions stressor. These results are within acceptable thresholds (Malhotra, Kim, \& Patil, 2006; Podsakoff, MacKenzie, Lee, \& Podsakoff, 2003), which indicate that common methods bias may not be a significant concern in our data.

\subsection{Hypotheses testing}

Table 3 shows the means, standard deviations, factor loadings and reliabilities (Cronbach Alpha - $\alpha$, and Composite Reliability - CR) for each construct. For the work relationships stressor $(\alpha=.878 ; C R=.908)$, the 6 items mapped on a single factor, all with loadings above .69. For the job control stressor $(\alpha=.878$; $C R=.917)$, the 4 items mapped on a single factor with loadings above .83 . For the job conditions stressor $(\alpha=.736$; $C R=.839)$, the 4 items mapped on a single factor with loadings above .63. We note that the all factor loadings and Cronbach Alpha values are greater than the respective thresholds of 0.6 and 0.7 (Nunnally, 1978), indicating high construct reliability. Table 4 shows the inter-construct correlations and square root of the average variance extracted (AVE). We note that for each work stressor, the square root of the AVE is greater than its correlations with the other work stressors, indicating convergent validity for each work stressor and discriminant validity 
among them (Wetzels, Odekerken-Schröder, \& Van Oppen, 2009). The distribution of email supplies and email values, their means and standard deviations are detailed in Figure $2^{8}$.

\section{Table 3: Construct Reliability, Mean, Standard Deviation, and Factor Loadings.}

\begin{tabular}{|l|c|c|c|}
\hline & Mean & $\begin{array}{c}\text { Standard } \\
\text { deviation }\end{array}$ & $\begin{array}{c}\text { Factor } \\
\text { loading }\end{array}$ \\
\hline Current extent of email use (i.e., Email Supplies) & 5.42 & 1.57 & \\
\hline the extent to which one interacts with others using email & & & \\
\hline Desired extent of email use (i.e., Email Values) & 5.11 & 1.43 & \\
\hline the extent to which one would like to interact with others using email & & & \\
\hline Work relationships stressor ( $\alpha=.878 ;$ CR $=.908)$ & 2.34 & 1.10 & \\
\hline (1) having poor relationships at work & 2.01 & 1.41 & 0.79 \\
\hline (2) feeling isolated & 2.67 & 1.56 & 0.82 \\
\hline (3) lacking support & 2.51 & 1.41 & 0.84 \\
\hline (4) unsure about what is expected from oneself & 2.34 & 1.46 & 0.79 \\
\hline (5) constantly criticized by one's superiors & 2.42 & 1.38 & 0.80 \\
\hline (6) intimidated by one's superiors & 2.08 & 1.09 & 0.69 \\
\hline Job control stressor ( $\alpha=.878 ;$ CR $=.917$ ) & 2.80 & 1.25 & \\
\hline (1) having little control over one's job & 3.1 & 1.45 & 0.84 \\
\hline (2) having little control over one's performance targets & 2.86 & 1.51 & 0.85 \\
\hline (3) having little control over one's decisions impacting one's job & 2.54 & 1.39 & 0.90 \\
\hline (4) decisions impacting one's job do not take into account one's inputs & 2.69 & 1.49 & 0.85 \\
\hline Job conditions stressor ( $\alpha=.736 ;$ CR = .839) & 2.67 & 1.08 & \\
\hline (1) finding one's job repetitive & 2.09 & 1.24 & 0.79 \\
\hline (2) one's job performance is monitored & 3.08 & 1.52 & 0.63 \\
\hline (3) one's working conditions are difficult & 2.97 & 1.50 & 0.84 \\
\hline (4) one's customers are difficult to deal with & 2.53 & 1.50 & 0.75 \\
\hline
\end{tabular}

Notes: $\alpha$ refers to Cronbach's alpha and CR to the composite reliability.

Table 4: Construct Correlations and Average Variance Extracted

\begin{tabular}{|l|c|c|c|c|c|}
\hline & $\mathrm{S}$ & $\mathrm{V}$ & $\mathrm{REL}$ & $\mathrm{CTRL}$ & $\mathrm{JOB}$ \\
\hline Email Supplies (S) & & & & & \\
\hline Email Values (V) & $.76^{\star \star}$ & & & & \\
\hline Work relationships stressor (REL) & -0.15 & $-.19^{\star}$ & .79 & & \\
\hline Job control stressor (CTRL) & -0.08 & $-.22^{\star}$ & $.76^{\star \star \star}$ & .86 & \\
\hline Job conditions stressor (JOB) & -0.12 & $-0.19^{\star}$ & $.74^{\star \star}$ & $.73^{\star \star \star}$ & .75 \\
\hline
\end{tabular}

${ }^{8}$ We note the high average value of email supplies. There are potentially two reasons for this. One, email may be extensively used in the organizations where our respondents worked. Indeed, office workers face ever increasing email use (e.g., Dabbish \& Kraut, 2006; Sumecki et al, 2011; Whittaker \& Sidner, 1996). Two, information acquisition literature suggests that individuals take in more rather than less information, especially in situations in which information is easy to obtain (e.g., Ackoff, 1967; Levine, Samet, \& Brahlek, 1975), which is the case with email, given its ubiquity. 
Notes: Numbers in bold indicate the square root of the average variance extracted (AVE) for each work stressor. ${ }^{\star} p<.05 ;{ }^{* \star} p<.01 ;{ }^{* \star \star} p<.001$

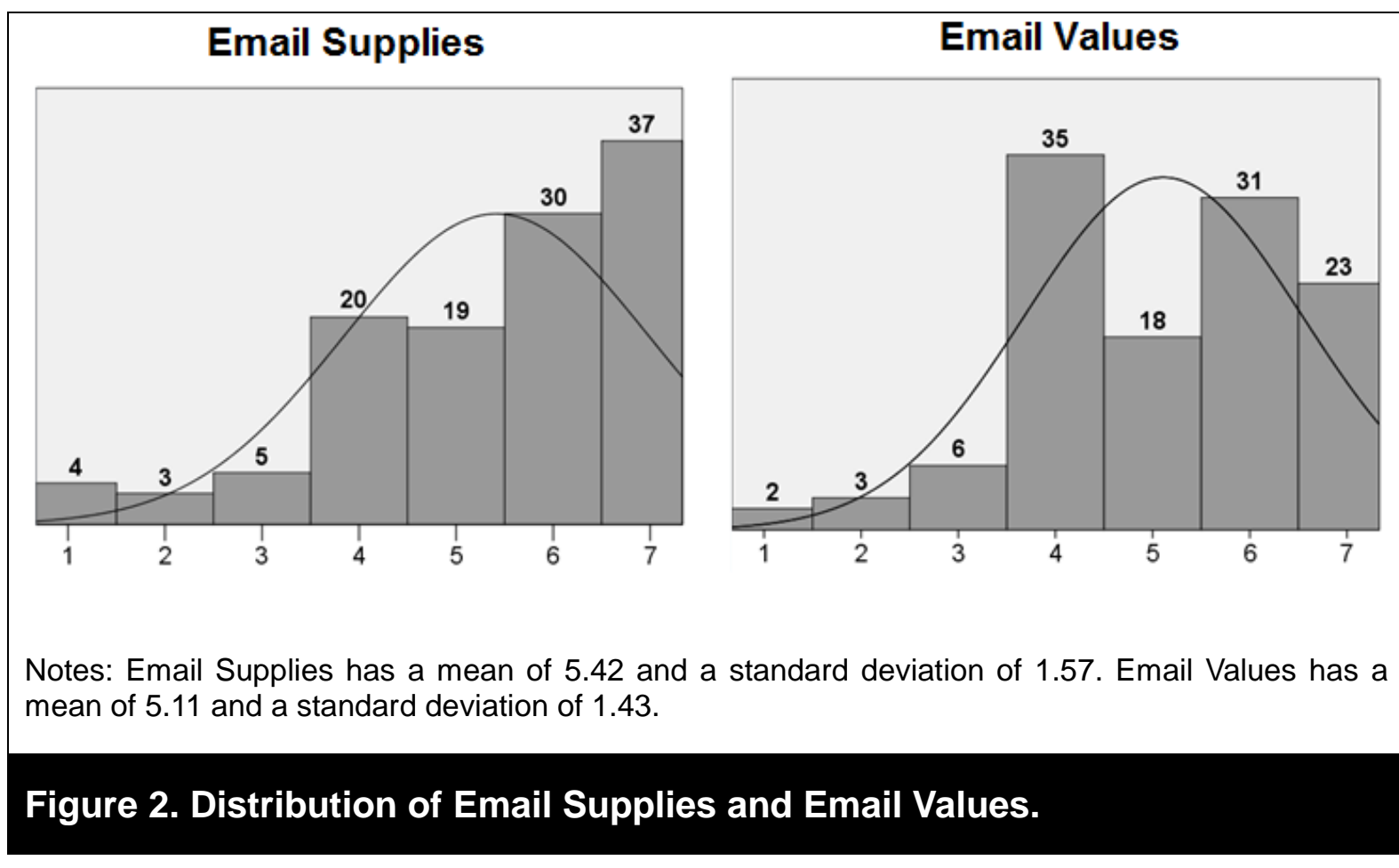

Following studies on person-environment fit, we used quadratic polynomial regressions (Klein et al., 2009) to test our hypotheses ${ }^{9}$. The following equation was analyzed, using $S$ for email supplies (i.e., the current extent of email use) and $\vee$ for email values (i.e., the desired extent of email use) and "Stressor" for either work relationships stressor, job control stressor, or job conditions stressor. We thus analyzed three equations, one for each stressor.

$$
\text { Stressor }=b_{0}+b_{1} S+b_{2} V+b_{3} S^{2}+b_{4} S V+b_{5} V^{2}+e
$$

\footnotetext{
${ }^{9}$ We used quadratic polynomial regressions (Klein, Jiang, \& Cheney, 2009) to calculate the value of email use excess or use deficit in testing our hypotheses. We calculated the coefficients of the first and second derivatives of Equation (1) for $\mathrm{S}=\mathrm{V}$ and $\mathrm{S}=-\mathrm{V}$, to assess the effect of email misfit (i.e., email use excess and email use deficit) and email fit on the three work stressors, as described in detail in Section 5.3. We did not use difference scores (i.e., S-V). Difference scores are not appropriate for our study because they (1) assume that supplies and values have the same magnitude of influence on the work stressors; and (2) have concerns over their reliability and validity in person-environment fit research (Edwards \& Parry, 1993; Klein et al., 2009).
} 
Equation (1) allows us to examine how email supplies and values will impact each stressor, as required by our hypotheses. The quadratic regressions allow us to examine curvilinear relationships between misfit and the three work stressors (Edwards \& Parry, 1993).

$\mathrm{S}$ and $\mathrm{V}$ were scale centered by subtracting 4 (i.e., mid-point of the 1-7 Likert Scale), which is the scale midpoint, in order to facilitate interpretation of the intercept and to reduce multicollinearity as commonly done in person-environment fit studies (e.g., Edwards \& Parry, 1993). We also added in this equation our control variables of age, sex, education, organization size, industry and managerial level, also mean-centered. To explore the effect of email fit and email misfit on the three stressors, we represented the equations in threedimensions (Figures 3, 4, 5 - Respective stressor in the z-axis, Email Supplies in the x-axis and Email Values in the y-axis) using response surface methodology (Edwards \& Parry, 1993). Response surface methodology analyzes the significance of slopes and curvatures across a two-dimensional surface in order to demonstrate whether they are significant or not. We next describe how we tested each hypothesis by analyzing Equation 1 and using the response surface method for $S, V$, and each of the three stressors. The results are shown in Figures 3, 4, 5 and in Tables 5, 6 and 7.

\section{Table 5: Hypothesis Testing Using Response Surface Methods}

\begin{tabular}{|c|c|c|}
\hline & Curve of email misft & Curve of email fit \\
\hline Curve of interest & $\begin{array}{l}\text { Supplies }=- \text { Values curve, which is the } \\
\text { curve representing the cases where } \\
\text { the current extent of email use is } \\
\text { diametrically opposite to the desired } \\
\text { extent of email use (e.g., it contains } \\
\text { the point } S=3, V=-3, S=2, V=-2 \text { etc). }\end{array}$ & $\begin{array}{l}\text { Supplies = Values curve, which } \\
\text { is the curve representing the } \\
\text { cases where the current and } \\
\text { desired extents of email use are } \\
\text { equal (e.g., it contains the points } \\
\mathrm{S}=3, \mathrm{~V}=3 \text { ). It is therefore the } \\
\text { curve on which email fit is } \\
\text { maximized. }\end{array}$ \\
\hline Equation for this curve & $\begin{array}{l}\text { Stressor }=b_{0}+\left(b_{1}-b_{2}\right) S+\left(b_{3}-b_{4}+\right. \\
\left.b_{5}\right) \mathrm{S}^{2}+e ;(\mathrm{S}=-\mathrm{V}) \text { in Equation } 1\end{array}$ & $\begin{array}{l}\text { Stressor }=b_{0}+\left(b_{1}+b_{2}\right) S+\left(b_{3}+\right. \\
\left.b_{4}+b_{5}\right) \mathrm{S}^{2}+e ; \quad(S=V) \text { in } \\
\text { Equation } 1\end{array}$ \\
\hline $\begin{array}{l}\text { Coefficient } \\
\text { representing the slope } \\
\text { of this curve at the } \\
\text { point } S=V=0 \text {. }\end{array}$ & $b_{1}-b_{2}$ (first derivative) & $b_{1}+b_{2}$ (first derivative) \\
\hline
\end{tabular}




\begin{tabular}{|c|c|c|}
\hline $\begin{array}{l}\text { Coefficient } \\
\text { representing the } \\
\text { curvature of this curve } \\
\text { at the point } \mathrm{S}=\mathrm{V}=0 \text {. }\end{array}$ & $b_{3}-b_{4}+b_{5}$ (second derivative) & $b_{3}+b_{4}+b_{5}$ (second derivative) \\
\hline $\begin{array}{l}\text { Results needed to } \\
\text { support the misfit } \\
\text { hypotheses }(\mathrm{H} 1 \mathrm{a}, \mathrm{H} 1 \mathrm{~b}, \\
\mathrm{H} 1 \mathrm{c})\end{array}$ & $\begin{array}{l}\text { The curve must be concave upward } \\
\text { (i.e., U-shaped) across the point } \\
S=V=0 \text {, implying that the coefficient } \boldsymbol{b}_{3} \\
-\boldsymbol{b}_{4}+\boldsymbol{b}_{5} \text { is significantly positive } \\
\text { (Edwards \& Parry, 1993). } \\
\text { AND } \\
\text { The tangent of the U-shaped must } \\
\text { have a zero slope at the } S=V=0 \text { point } \\
\text { implying that the value of the stressor } \\
\text { at the } S=V=0 \text { point is the lowest. This } \\
\text { is the case when the coefficient } \boldsymbol{b}_{1}-\boldsymbol{b}_{2} \\
\text { is not significantly different than } \\
\text { zero (Edwards \& Parry, 1993) }\end{array}$ & \\
\hline $\begin{array}{l}\text { Results needed to } \\
\text { support the fit } \\
\text { hypotheses }(\mathrm{H} 2 \mathrm{a}, \mathrm{H} 2 \mathrm{~b} \text {, } \\
\mathrm{H} 2 \mathrm{c} \text {. }\end{array}$ & & $\begin{array}{l}\text { The curve must be a straight } \\
\text { horizontal line (i.e., no curvature } \\
\text { and a zero slope), implying that } \\
\text { both }\left(\boldsymbol{b}_{1}+\boldsymbol{b}_{2}\right) \text { and }\left(\boldsymbol{b}_{3}+\boldsymbol{b}_{4}+\boldsymbol{b}_{5}\right) \\
\text { must not significantly differ } \\
\text { from zero (Edwards \& Parry, } \\
\text { 1993). }\end{array}$ \\
\hline
\end{tabular}

Table 6: Polynomial Quadratic Regressions of the Stressors on Email Supplies and Email Values

\begin{tabular}{|c|c|c|c|c|c|c|c|}
\hline & \multicolumn{7}{|c|}{ Results from quadratic regression in Equation 1} \\
\hline Outcome & $b 0$ & $b 1(S)$ & $b 2(V)$ & $b 3\left(S^{2}\right)$ & $b 4(S V)$ & $b 5\left(V^{2}\right)$ & $R^{2}$ \\
\hline $\begin{array}{c}\text { Work relationship } \\
\text { stressor }\end{array}$ & 2.547 & 0.109 & -0.102 & 0.018 & $-0.263^{\star}$ & 0.163 & $0.096^{\star \star}$ \\
\hline Job control stressor & 2.967 & $0.286^{\star}$ & $-0.303^{\star}$ & 0.028 & $-0.328^{\star \star}$ & 0.218 & $0.158^{\star \star \star}$ \\
\hline Job conditions stressor & 2.855 & $0.211^{\star}$ & $-0.242^{\star}$ & -0.016 & $-0.306^{\star \star}$ & $0.262^{\star \star}$ & $0.201^{\star \star \star}$ \\
\hline
\end{tabular}

Notes: Controlled for Age, Sex, Education, Organization size, Industry and Managerial Level. $R^{2}$ is adjusted. $S$ refers to the current extent of email use, and $V$ to the desired extent of email use. $b 1, b 2$, $b 3, b 4$, and $b 5$ are the coefficients on $S, V, S^{2}, S V$, and $V^{2}$, respectively; $b 0$ is the intercept and is significant. * $\mathrm{p}<.05 ;{ }^{* *} \mathrm{p}<.01 ;{ }^{* \star *} \mathrm{p}<.001$

Table 7: Slopes and Curvatures Along the Curves of Interest

\begin{tabular}{|l|c|c|c|c|}
\hline & \multicolumn{2}{|c|}{$\begin{array}{c}\text { Shape along the curve of email } \\
\text { fit } \\
(S=V)\end{array}$} & \multicolumn{2}{c|}{$\begin{array}{c}\text { Shape along the curve of email misfit } \\
(S=-V)\end{array}$} \\
\hline Outcome variable & $\begin{array}{c}\text { Slope } \\
\mathrm{b}_{1}+\mathrm{b}_{2}\end{array}$ & $\begin{array}{c}\text { Curvature } \\
\mathrm{b}_{3}+\mathrm{b}_{4}+\mathrm{b}_{5}\end{array}$ & $\begin{array}{c}\text { Slope } \\
\mathrm{b}_{1}-\mathrm{b}_{2}\end{array}$ & $\begin{array}{c}\text { Curvature } \\
\mathrm{b}_{3}-\mathrm{b}_{4}+\mathrm{b}_{5}\end{array}$ \\
\hline Work relationship stressor & 0.006 & $-0.082^{\star}$ & 0.211 & $0.443^{\star}$ \\
\hline Job control stressor & -0.017 & -0.082 & 0.59 & $0.574^{\star \star}$ \\
\hline Job conditions stressor & -0.03 & -0.06 & 0.453 & $0.553^{\star \star}$ \\
\hline
\end{tabular}

Notes: Controlled for Age, Sex, Education, Organization size, Industry and Managerial Level. $S$ refers to the current extent of email use, and $V$ to the desired extent of email use. $b 1, b 2, b 3, b 4$, and $b 5$ are the coefficients on $S, V, S^{2}, S V$, and $V^{2}$, respectively. ${ }^{*} p<.05 ;{ }^{* *} p<.01 ;{ }^{\star \star \star} p<.001$ indicate significance of difference from zero. 

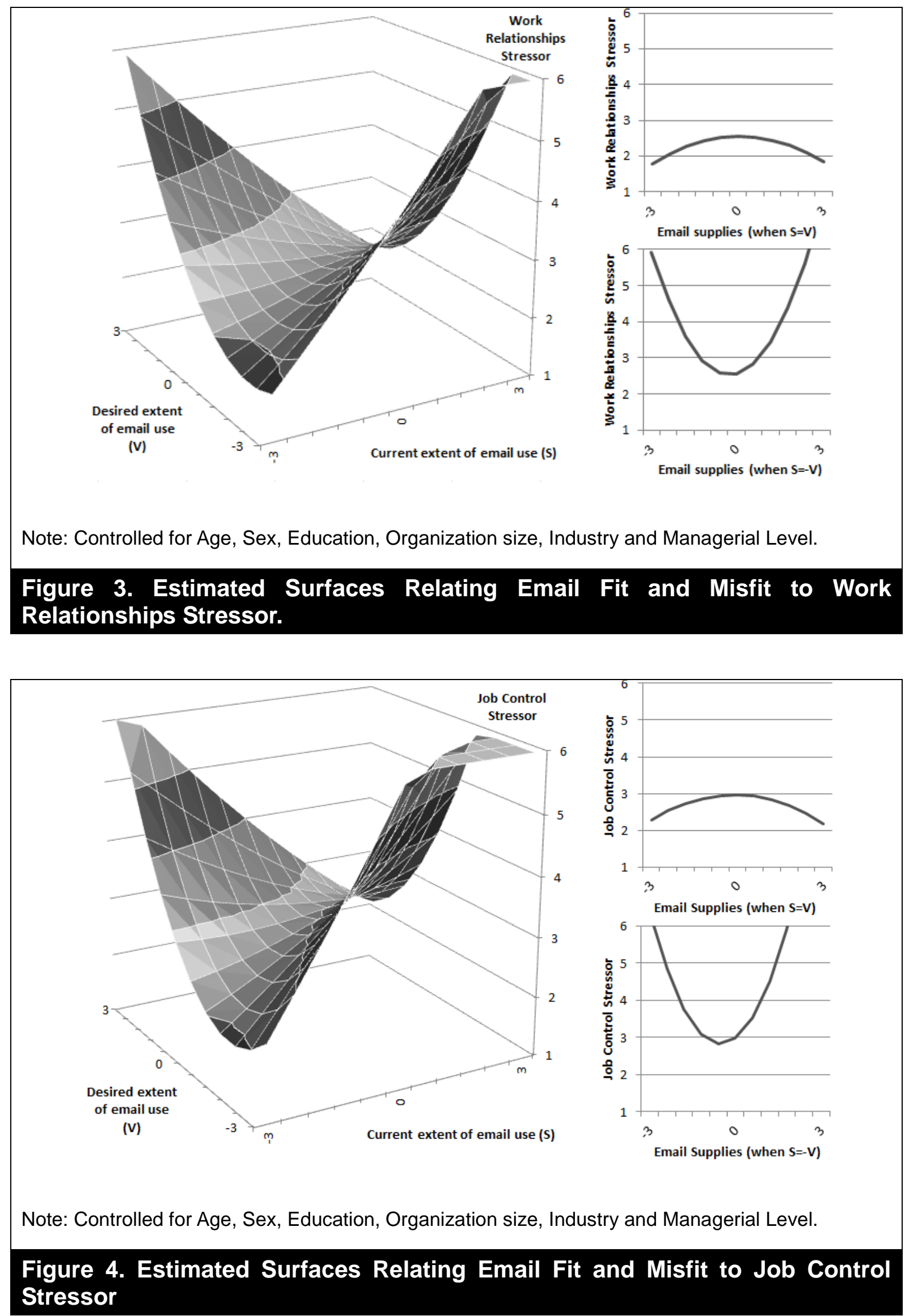


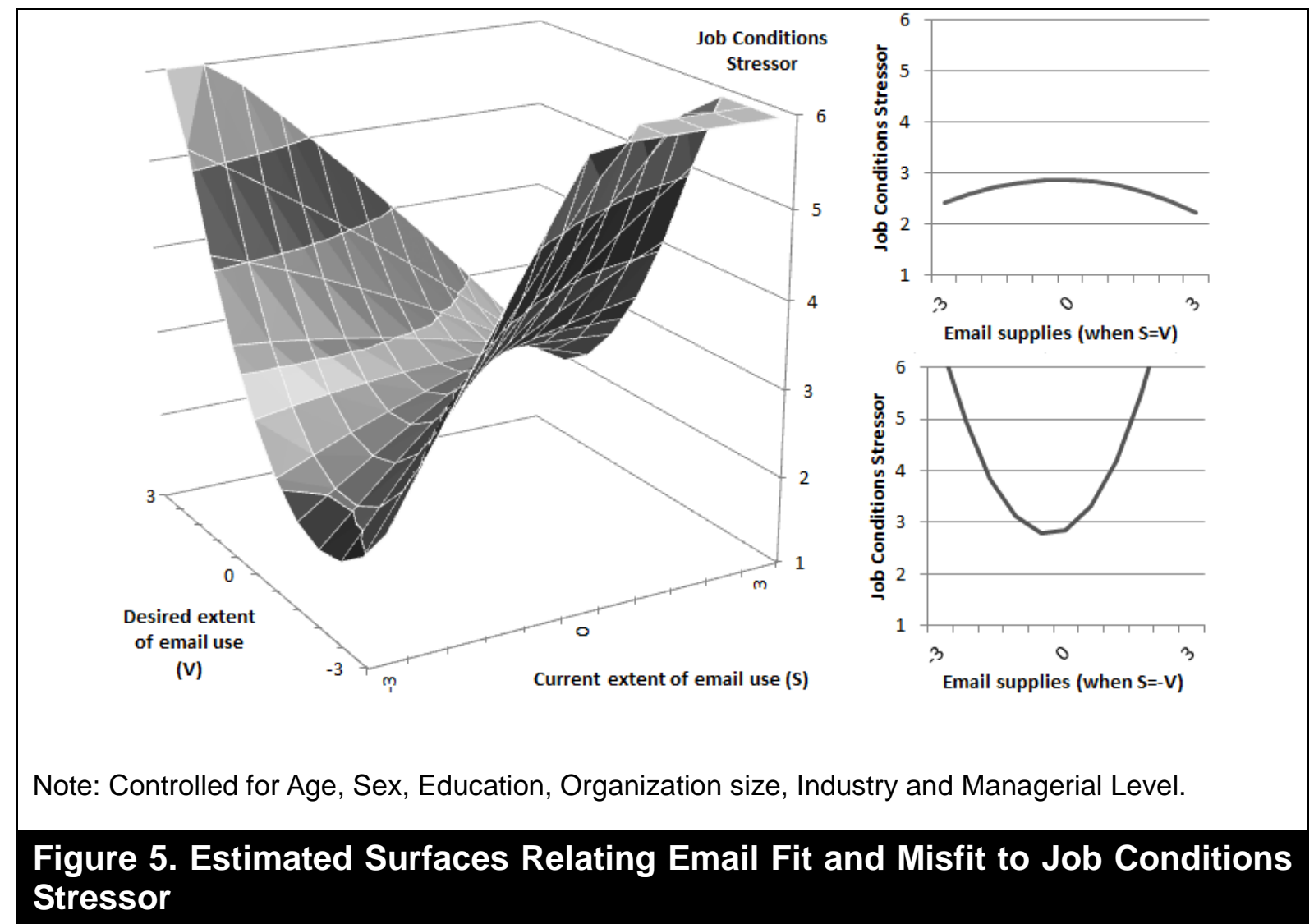

\section{Misfit hypotheses (H1a, H1b, H1c)}

The three misfit hypotheses predicted that the higher individuals experience email misfit (i.e., when the current extent of email use deviates from the desired extent), the higher they experience the workplace stressors. These hypotheses are tested by looking at the shape of the $S=-V$ curve (Edwards \& Parry, 1993), which is the curve on the surface representing the cases where the current extent of email use is diametrically opposed to the desired extent of email use (See Table 5).

For these hypotheses to be supported, this curve should be concave upward and the $S=V=0$ point should be located on its axis of symmetry (Edwards \& Parry, 1993). Setting $V$ equals to $-S$ in Equation (1) to capture this curve of email misfit and solving for coefficients (see Table 5) indicates that $b_{1}-b_{2}$ represents the slope (i.e., the first derivative) and $b_{3}-b_{4}+b_{5}$ represents the curvature (i.e., the second derivative) of the tangent at the $S=V=0$ point. Thus for the $S=-V$ curve to be concave upward across the $S=V=0$ point, the tangent at this point 
must have a positive curvature, meaning that $b_{3}-b_{4}+b_{5}$ would need to be significantly positive (Edwards \& Parry, 1993). Additionally, for the particular stressor to have the lowest value at the point of email fit, the $S=V=0$ point should be located on the axis of symmetry of this U-shaped curve. According to the person-environment fit literature (Edwards \& Parry, 1993), this is tested by looking at the curve of email misfit $(S=-V)$ and the slope of the tangent at the point $S=V=0$ (i.e., the coefficient $b_{1}-b_{2}$ ) (See Table 5) (Edwards \& Parry, 1993). The $S=V=0$ point is located on the axis of symmetry of the $U$-shaped curve when the slope of the tangent at this point is zero (i.e., when the coefficient $b_{1}-b_{2}$ is not significantly different from zero).

The hypotheses were supported for all the three stressors (See Tables 6, 7 and Figures 3, 4 and 5). Looking at Table 7 we first see that the surfaces were indeed concave upward facross the $S=V=0$ point for the work relationships stressor (Curvature $=b_{3}-b_{4}+b_{5}=0.443$, $p<.05$ ), job control stressor (Curvature $=b_{3}-b_{4}+b_{5}=0.574, p<.01$ ) and job conditions stressor (Curvature $=b_{3}-b_{4}+b_{5}=0.553, p<.01$ ). We then see that the slopes of the tangent at the $S=V=0$ point were not significantly different from zero for the work relationships stressor (Slope $=b_{1}-b_{2}=0.211, p>.05$ ), job control stressor (Slope $=b_{1}-b_{2}=$ $0.590, p>.05$ ) and job conditions stressor (Slope $=b_{1}-b_{2}=0.453, p>.05$ ). That is, for each $U$-shaped curve, the $S=V=0$ point was located on the axis of symmetry. These are illustrated in the left side graphs of Figures 3, 4 and 5 where we clearly see the curvilinear shape of the diagonal running from the back-left corner to the front right corner. We also see in the bottom right side graphs $(S=-V)$ that the misfit curves are clearly concave upward. So, $\mathbf{H} \mathbf{1 a}, \mathbf{H} \mathbf{1 b}$ and $\mathrm{H} 1 \mathrm{C}$ are supported. In other words, the higher individuals experienced email misfit, the higher they perceived the workplace stressors. Further, the effects are curvilinear.

\section{Fit hypotheses (H2a, H2b, H2c)}

The three fit hypotheses theorized that the level of the stressors will not increase when the extent of email use increases as long as email fit is maintained (i.e., when the current extent of email use equals the desired extent). To investigate these hypotheses, we examined the $S$ 
$=V$ curve, representing the cases where the current and desired extents of email use are equal (e.g., it contains the points $S=3, V=3$ or $S=-3, V=-3$ ). It is therefore the curve on which email fit is maximized (i.e., the curve of email fit).

Setting $S$ equal to $V$ in Equation (1) to capture this curve of email fit and solving for coefficients (see Table 5) indicates that $b_{1}+b_{2}$ represents the slope (i.e., the first derivative) and $b_{3}+b_{4}+b_{5}$ represents the curvature (i.e., the second derivative) of the surface at the point $S=V=0$ (Edwards \& Parry, 1993). For the fit hypotheses to be supported, the curve of email fit should be a straight horizontal line (i.e., no curvature and a zero slope), meaning that both $b_{1}+b_{2}$ and $b_{3}+b_{4}+b_{5}$ must not significantly differ from zero (See Table 5).

Consistent with the above, the $S=V$ curve showed no slope and no significant curvature for the job control stressor (Curvature $=b_{3}+b_{4}+b_{5}=-0.082, p>.05$; Slope $=b_{1}+b_{2}=-0.017, p$ $>$.05) and the job conditions stressor (Curvature $=b_{3}+b_{4}+b_{5}=-0.06, p>.05$; Slope $=b_{1}+$ $b_{2}=-0.03, p>.05$ ) (see Tables 6 and 7). This is also shown in the top-right graphs of Figures 4 and 5 where the curvatures of the $S=V$ curves are not statistically significant. Thus, H2b and H2c are supported. In other words, the perceived levels of these two stressors were the same at all values of the current extent of email use, as long as email fit was maintained.

Regarding the work relationship stressor $(\mathrm{H} 2 \mathrm{a})$, the coefficient $b_{3}+b_{4}+b_{5}$ was significantly negative but $b_{1}+b_{2}$, was not significantly positive. This means that the $S=V$ curve was flat at the origin, but convex (Curvature $=b_{3}+b_{4}+b_{5}=-0.082, p<.05$; Slope $=b_{1}+b_{2}=0.006, p>$ .05) (See Figure 3). This shows that when current extent of email use matches the desired extent, work relationships stressor is perceived at a lower level when the current extent of email use is high or low, and at a higher level when the current extent of email use was moderate. That is, achieving email fit with either high or low current extents of email use is less stressful in terms of work relationships than achieving fit with a moderate extent. 


\subsection{Limitations}

Before describing the study's contributions, we make a note of its limitations. First, notwithstanding the advantages of the online panel that we discussed in Section 5.2, this approach to data collection has limitations. Online panels restrict the range of participants to internet users. Furthermore, sampling is non-random given that participants self-enroll - thus there may be biases that are not clearly understood. We note however, that most studies on email use also use non-random sampling techniques such as focusing on employees of particular organizations or even on students. To mitigate potential concerns, we applied a number of controls and also compared our sample to the larger population from which the sample is drawn. Our results hold for a sample that is generally representative of the overall US population of working adults, controlled for age, sex, education, organization size, industry and managerial/hierarchical position, and is representative in its general behavioral well-being, of employees in organizations from the US, UK and Western Europe. However, conducting the study on a set of respondents recruited through a different method may increase the confidence of the results.

Secondly, the measurement of current and desired extent of email use provided a basis for the survey's respondents to report them in line with the three desired criteria commensurability, subjectivity and simplicity. While email use has a number of aspects (volume, frequency, intensity etc.), they all contribute to the email load the individual deals with. An overall assessment of the 'extent of email' helped us to keep the assessment attribute simple and enabled us to focus on the difference of that attribute rather than the absolute values, for evaluating email fit and misfit. Such a measure was appropriate, given that our objective was to explain, as a first step, how the extent of email use is appraised as stressful by individuals. Future studies can take this as a departure point and adopt multiple attributes of email use as measurement criteria. These could include self-reported number of emails received and sent per day, average email length, time spent using email, email complexity, email urgency etc., using open ended scales. That could also enable the parsing 
of the individual experiencing email use excess and email use deficit along different criteria. For instance, an individual may appreciate a low extent of email use, regardless of whether they think they are missing important messages. In such a case, he or she may experience email fit with respect to volume of email, but misfit with respect to message importance. Given the number of different aspects and possible contexts of email use, the matter of measuring email use is not a simple one; measures should be selected in line with the objective of the study. Future research could adopt email-by-email analysis or controlled laboratory experiments to get at the effects of the more qualitative characteristics of email. Further in addition to considering supplies-values fit, future research could also examine fit between the abilities of the individual to write, filter and archive email (Soucek \& Moser, 2010), and the demands for such abilities required by the job.

Third, as with all survey research, the cross-sectional nature of the study along with selfreported data can be imbued with the problem of establishing causality. For instance, it could be argued that stress in the workplace such as bad job conditions leads to desire to achieve email fit (through less or more acquisition of information), or that stressful work environments and poor relationships with colleagues lead to problematic use of email. Future longitudinal or qualitative studies could investigate these sorts of issues.

\section{Discussion}

We set out in this research to explain why the extent of email use is appraised as a source of workplace stress. In order to do this, we drew from information acquisition and personenvironment fit theories to theoretically and empirically understand the appraisal process. We found that: (1) As email misfit increases from the point of email fit on both the email use excess and the email use deficit sides, individuals experience a higher extent of workplace stressors; (2) the change in the increase of stressors with the increase in misfit is nonlinear and symmetric for both email use excess and email use deficit; and (3) that the level of stressors perceived at email fit does not vary significantly with increase in the current extent of email use. We next evaluate the study's contributions to theory and practice. 


\subsection{Theoretical contributions}

Our first theoretical contribution is to effect a conceptual integration between the person environment fit (e.g., Edwards et al., 2006) and information acquisition literatures (e.g., Browne \& Pitts, 2004; Connolly \& Gilani, 1982; Connolly \& Thorn, 1987). Drawing from information acquisition concepts such as over- and under- acquisition and stopping rules as a basis for examining email related fit, provides a theoretical basis for studies to further examine the excess and deficit sides of misfit by applying related concepts such as information acquisition costs (e.g., email processing time and resources) and decision costs associated with excess or deficit information (e.g., email overload and underload). Conversely, the application of the person environment approach to qualify the cognitive appraisal and judgement associated with information under - and over - acquisition provides

a new conceptual and empirical apparatus that future studies can further examine, in studying outcomes associated with these two conditions. Information acquisition studies have considered the effects of over- and under-acquisition on parameters such as information quality and decision quality and cost, in the context of systems development, system design and project management, and of experimental tasks involving consumer buying and production planning. Our results suggest that email use excess and email use deficit, to the extent that they represent respectively, over and under acquisition of information, when appraised through the lens of email fit/misfit, can be detrimental because of associated effects with workplace stressors. This is a new effect associated with under and over acquisition of information. These contributions provide interesting and novel theoretical links among the literatures on person-environment fit and information acquisition, and provide a fertile conceptual and empirical ground for future research.

We further note as a point of discussion, that had the $b_{1}-b_{2}$ coefficients been significantly negative, the tangent at the $S=V=0$ point would have had a negative slope. This would imply that as the email misfit increased, the value of the stressor would exceed its value at email fit, at a lower value of misfit (i.e., sooner) on the email use deficit side, than on the email use 
excess side. That is, the rate of change of the increase in the stressor would be higher on the email use deficit side than on the email use excess side. There is an interesting potential connection here to the information acquisition literature. Prospect Theory suggests that individuals perceive differences due to the current condition being less than the desired, to be more salient in their negative impacts, than they consider like differences due to the current condition being more than the desired in their positive impacts. The former are cognitively more prominent for the individual and show a stronger relationship to the extent of outcomes (Kahneman \& Miller, 1986). For instance, losses are considered more salient than gains even though they may be of the same magnitude because negative events require an individual's problem solving and/or corrective action to ensure survival, unlike positive events. Information acquisition literature similarly argues that under-acquisition is arguably a more significant concern (Browne \& Pitts, 2004). In systems requirements for instance, under-acquisition can lead to problems in design and implementation, and potential failure of the system, deemed more serious than the effects of over-acquisition, which are primarily wasted time and resources (Browne \& Pitts, 2004). However, we do not find this greater salience of the under-acquisition side suggested by these studies, to be the case in our study. In this paper, we make an initial integration between the person environment fit and information acquisition literatures by looking at the differences between email misfit and fit. We believe future research can take this forward to investigate if email use excess and email use deficit may be associated with stressors differently.

Our second contribution is to the literature on the negative workplace effects of email use (e.g., Barley et al., 2011; Dabbish \& Kraut, 2006). In theoretically explaining the process of stressor appraisal from email use, we showed that email misfit is salient to the experience of high levels of job control, job conditions and work relationships stressors. The discrepancy between current and desired extent of use is appraised as being associated with stressors. This implies that not only too much but also too little email is associated with stressors. A given extent of email use can thus be associated with both a high and low level of stressors, 
depending on how close it is to his or her desired extent of email use. Further, the same individual can experience increasing email use to be less stressful in the email use deficit region and more stressful in the email use excess region. We thus highlight the significance of the individual's appraisal in assessing stress-related effects of email load, by theoretically introducing and empirically examining the concepts of email misfit and email fit to this literature. The concept of email overload should thus be re-visited, in order to capture email use ranging from email use deficit to email use excess. In this context, it is possible to suggest that email use excess as examined in this paper is associated with the perception of email overload examined in the literature. Email use deficit on the other hand is a condition of email use sub-par to what the individual wants. It can be associated with a perception of "not enough" email or what could be characterized as 'email underload'. This notion of email underload is a new theoretical contribution to this literature; to the best of our knowledge, it has not been examined before.

Our third contribution is to the literature that examines the stress creating effects of IT in the form of technostress (e.g., Ayyagari et al., 2011; Tarafdar et al., 2007). Although this literature discusses various stressors due to use of IT (Tarafdar et al., 2007), the appraisal process that explains under what conditions the stressors are perceived as such has not received much attention (Tarafdar, Cooper, \& Stich, 2017). In this regard, we report an analytical and empirical construction of fit and misfit with respect to extent of email use, and demonstrate an empirical association between misfit and work stressors. In doing so, we shed a novel light on the conditions under which the attributes relating to technology (in this case email) use, can be appraised as a stressor. We show that IT use is appraised as stressful when it both exceeds and fails to meet the user's preference. To the best of our knowledge this is the first study to theoretically conceptualize and empirically examine a relationship between a technology use related attribute and perceived stressors. Further, this literature has considered mostly the 'too much' aspect of IT (e.g., Ayyagari et al., 2011; Tarafdar et al., 2007) with an implicit assumption that it is associated with stressors. By 
introducing the concepts of fit and misfit as means of stressor appraisal, we suggest that study of stressors associated with IT use should consider both excess related and deficit related aspects of attributes and use of technology. Finally, while this literature describes a number of IT related stressors (e.g., Ayyagari et al., 2011; Tarafdar et al., 2007), it does not examine the relationship between the use of IT and the three stressors we study in this paper.

As a method related contribution, the paper tackles the assessment of the effects of email use by evaluating the effects of email fit and email misfit, based on insights from personenvironment fit research (Klein et al., 2009). This method allowed us to assess separately the environment (i.e., current extent to which the individual uses email) and the person (i.e., extent to which the individual desires to use email). Such separation acknowledges the importance of individuals' preferences by asking them about their values. Further, it allows us to investigate both email use excess and email use deficit. We are not aware of any study that has investigated the effects of email use in this manner. Email literature primarily combines the individual's perception (i.e., the person aspect) and the technology's characterization (i.e., the environment aspect) into single items such as 'I feel overwhelmed with my email', without separating them out. The separation of measurement of supplies and values makes it possible to analytically qualify email fit and misfit, and examine their relationships with stressors, instead of relying on the individual's self-reported response of email overload being stressful.

This study opens up a number of new directions for future research. Other factors salient to the appraisal process such as personality traits (Reinke \& Chamorro-Premuzic, 2014), organizational norms and culture, and work-life situations can be examined. Second, stress research suggests that the level of misfit/fit could change over time as the individual becomes used to higher levels of demands (Lazarus, 1990). Longitudinal research designs that study email use and email fit/misfit over time could capture such a process. Third, future research can examine how individuals, once they have appraised their email fit and misfit, 
can cope with them through email management techniques. Fourth, the idea of why a mismatch of desired and current extents of email use happens, is an intriguing one that bears investigation. For instance, email use excess and email use deficit can be considered as potential consequences of, for example, poor conditions at work such as a poorly managed workplace and bad communication habits among employees. Fifth, future studies can also examine appraisal of email use as an opportunity, with the potential for positive outcomes (Tarafdar et al., 2017). Sixth, for a more holistic understanding of potential stress from use of workplace communication technologies, email use can be examined together with use of other workplace communication technologies such as instant messaging and video conferencing. Finally, post-hoc tests using piecewise linear regression (Edwards, 1994) revealed the overall linear rate of increase of the stressors to be slightly greater on the email use excess side than the email use deficit side. Future studies could further examine this finding through more refined hypothesis and analysis.

\subsection{Practical contributions}

Emerging practical concerns are beginning to focus on the problems associated with onesize-fits-all solutions and interventions to deal with phenomena such as technostress and information overload (Tarafdar, D'Arcy, Turel, \& Gupta, 2015), where a key assumption is that everyone wants 'less'. Our results provide implications for practice and policy that suggest differently.

First, our results direct managerial attention to the individual's preferences in dealing with email load. They suggest that in addition to too much email, even too little email can be stressful. They show that not everyone wants less email than what they receive. If the individual appraises his or her email use to be satisfying, the levels of stressors are low, regardless of the extent itself. Organizational policies that institute one size fits all solutions such as outright or after-work email bans, as has recently been the case (Pillet \& Carillo, 2016; Williams, 2011), are therefore not necessarily helpful because they assume that everyone receives excess email than what they would like, and do not give individual 
employees choice or flexibility in the matter of email use. It is not possible for such solutions to help individuals in the email use deficit condition because they do not acknowledge the existence of this condition.

Second, organizational policies could alert employees to individual differences in email use and encourage them to be mindful and empathetic about such differences. At the very least, such practices would make employees aware of the possibility of both email overload and underload among their colleagues. Employees should be encouraged to reflect on their own email use. While it is not possible to identify the 'right' or a 'sweet spot' of email use, employees could be encouraged to reflect on their preferences regarding email use. Relatedly, employees should be encouraged to be aware that their email use might affect their colleagues. While it is not possible to be certain about colleagues' email fits and misfits, the realization that one's own email could potentially create email excess for others may be an important step in addressing common email use behaviors such as mass Cc'ing. Conversely, the realization that one's lack of email could lead to email deficit for colleagues may result in more considered email responses from employees. To the best of our knowledge, few organizations consider these sorts of guidelines in their technology management initiatives, guidelines that could help managers and employees consider more carefully, their email use habits.

To conclude, our paper develops theoretical understanding of conditions under which the individual's extent of email use can be associated with certain workplace stressors through email misfit and email fit. Our study suggests that rather than looking at 'too much' email use as being uniformly associated with higher levels of stress, it is more instructive to understand under what conditions individuals consider their email use as stress-creating. Email use has both a misfit-related 'dark' side and a fit-related 'bright' side. Given the perennial importance of email in the workplace, these are interesting findings that future research can build on. 


\section{References}

Ackoff, R. L. (1967). Management misinformation systems. Management science, 14(4), B147.

Ayyagari, R., Grover, V., \& Purvis, R. (2011). Technostress: Technological Antecedents and Implications. MIS Quarterly, 35(4), 831-858.

Barber, L. K., \& Santuzzi, A. M. (2015). Please Respond ASAP: Workplace Telepressure and Employee Recovery. Journal of Occupational Health Psychology, 20(2), 172-189.

Barley, S. R., Meyerson, D. E., \& Grodal, S. (2011). E-mail as a Source and Symbol of Stress. Organization Science, 22(4), 887-906.

Barron, G., \& Yechiam, E. (2002). Private e-mail requests and the diffusion of responsibility. Computers in Human Behavior, 18(5), 507-520.

Baruch, Y. (2005). Bullying on the net: adverse behavior on e-mail and its impact. Information \& Management, 42(2), 361-371.

Bond, F. W., \& Bunce, D. (2003). The Role of Acceptance and Job Control in Mental Health, Job Satisfaction, and Work Performance. Journal of Applied Psychology, 88(6), 1057-1067.

Brandon, D. M., Long, J. H., Loraas, T. M., Mueller-Phillips, J., \& Vansant, B. (2014). Online Instrument Delivery and Participant Recruitment Services: Emerging Opportunities for Behavioral Accounting Research. Behavioral Research in Accounting, 26(1), 1-23.

Brown, R., Duck, J., \& Jimmieson, N. (2014). E-mail in the Workplace: The Role of Stress Appraisals and Normative Response Pressure in the Relationship Between E-mail Stressors and Employee Strain. International Journal of Stress Management, 21(4), 325-347.

Browne, G. J., \& Pitts, M. G. (2004). Stopping rule use during information search in design problems. Organizational Behavior and Human Decision Processes, 95(2), 208-224. 
Browne, G. J., Pitts, M. G., \& Wetherbe, J. C. (2007). Cognitive stopping rules for terminating information search in online tasks. MIS quarterly, 89-104.

Byron, K. (2008). Carrying Too Heavy a Load? The Communication and Miscommunication of Emotion by Email. Academy of Management Review, 33(2), 309-327.

Caplan, R. D. (1987). Person-environment fit theory and organizations: Commensurate dimensions, time perspectives, and mechanisms. Journal of Vocational Behavior, 31(3), 248-267.

Cavazotte, F., Heloisa Lemos, A., \& Villadsen, K. (2014). Corporate smart phones: professionals' conscious engagement in escalating work connectivity. New Technology, Work and Employment, 29(1), 72-87.

Chandra, A., \& Krovi, R. (1999). Representational congruence and information retrieval: Towards an extended model of cognitive fit. Decision Support Systems, 25(4), 271-288.

Chidambaram, L., \& Tung, L. L. (2005). Is out of sight, out of mind? An empirical study of social loafing in technology-supported groups. Information Systems Research, 16(2), 149168.

Connolly, T., \& Gilani, N. (1982). Information search in judgment tasks: A regression model and some preliminary findings. Organizational Behavior and Human Performance, 30(3), 330-350.

Connolly, T., \& Thorn, B. K. (1987). Predecisional information acquisition: Effects of task variables on suboptimal search strategies. Organizational Behavior and Human Decision Processes, 39(3), 397-416.

Cooper, C. L., Dewe, P. J., \& O'Driscoll, M. P. (2001). Organizational stress: A review and critique of theory, research, and applications. Thousand Oaks, CA: SAGE Publications. 
Dabbish, L. A., \& Kraut, R. E. (2006). Email overload at work: an analysis of factors associated with email strain. In Proceedings of the 2006 20th anniversary conference on Computer supported cooperative work (pp. 431-440). Banff, Alberta, Canada: ACM.

Danna, K., \& Griffin, R. W. (1999). Health and well-being in the workplace: A review and synthesis of the literature. Journal of management, 25(3), 357-384.

de la Rupelle, G., Fray, A.-M., \& Kalika, M. (2014). Messagerie électronique, facteur de stress dans le cadre de la relation managériale. Revue de gestion des ressources humaines, 91(1), 13-28.

Derks, D., \& Bakker, A. B. (2010). The Impact of E-mail Communication on Organizational Life. Cyberpsychology, 4(1).

Derks, D., van Duin, D., Tims, M., \& Bakker, A. B. (2015). Smartphone use and work-home interference: The moderating role of social norms and employee work engagement. Journal of Occupational and Organizational Psychology, 88(1), 155-177.

Diamantopoulos, A., Sarstedt, M., Fuchs, C., Wilczynski, P., \& Kaiser, S. (2012). Guidelines for choosing between multi-item and single-item scales for construct measurement: a predictive validity perspective. Journal of the Academy of Marketing Science, 40(3), 434449.

Donald, I., Taylor, P., Johnson, S., Cooper, C., Cartwright, S., \& Robertson, S. (2005). Work environments, stress, and productivity: An examination using ASSET. International Journal of Stress Management, 12(4), 409-423.

Ducheneaut, N., \& Watts, L. A. (2005). In Search of Coherence: A Review of E-Mail Research. Human-Computer Interaction, 20(1/2), 11-48. 
Edwards, J. R. (1994). The study of congruence in organizational behavior research: Critique and a proposed alternative. Organizational behavior and human decision processes, 58(1), 51-100.

Edwards, J. R. (1996). An Examination of Competing Versions of the Person-Environment Fit Approach to Stress. Academy of Management Journal, 39(2), 292-339.

Edwards, J. R., Cable, D. M., Williamson, I. O., Lambert, L. S., \& Shipp, A. J. (2006). The phenomenology of fit: linking the person and environment to the subjective experience of person-environment fit. Journal of Applied Psychology, 91(4), 802.

Edwards, J. R., \& Parry, M. E. (1993). On the Use of Polynomial Regression Equations as an Alternative to Difference Scores in Organizational Research. Academy of Management Journal, 36(6), 1577-1613.

Edwards, J. R., \& Van Harrison, R. (1993). Job demands and worker health: Threedimensional reexamination of the relationship between person-environment fit and strain. Journal of Applied Psychology, 78(4), 628.

Faragher, E. B., Cass, M., \& Cooper, C. L. (2005). The Relationship between Job Satisfaction and Health: A Meta-Analysis. Occupational and Environmental Medicine, 62(2), 105-112.

Faragher, E. B., Cooper, C. L., \& Cartwright, S. (2004). A shortened stress evaluation tool (ASSET). Stress and Health, 20(4), 189-201.

French, J. R., Caplan, R. D., \& Van Harrison, R. (1982). The mechanisms of job stress and strain (Vol. 8). New York: Wiley.

Friedman, R. A., \& Currall, S. C. (2003). Conflict escalation: Dispute exacerbating elements of e-mail communication. Human Relations, 56(11), 1325-1347. 
Gettys, C. F., \& Fisher, S. D. (1979). Hypothesis plausibility and hypothesis generation. Organizational Behavior and Human Performance, 24(1), 93-110.

Golden, T. D., \& Veiga, J. F. (2005). The Impact of Extent of Telecommuting on Job Satisfaction: Resolving Inconsistent Findings. Journal of Management, 31(2), 301-318.

Hogan, B., \& Fisher, D. (2006). A scale for measuring email overload (No. TR-2006-65) (pp. 1-3). Microsoft Research Technical Report.

Jackson, T. W., Dawson, R., \& Wilson, D. (2003). Reducing the effect of email interruptions on employees. International Journal of Information Management, 23(1), 55-65.

Jennings, D., Amabile, T. M., \& Ross, L. (1982). Informal covariation assessment: Databased versus theory-based judgments. In D. Kahneman, P. Slovic, \& A. Tversky (Eds.), Judgment under uncertainty: Heuristics and biases. Cambridge: Cambridge University Press.

Johnson, S., \& Cooper, C. (2003). The construct validity of the ASSET stress measure. Stress and Health, 19(3), 181-185.

Kahneman, D., \& Miller, D. T. (1986). Norm theory: Comparing reality to its alternatives. Psychological review, 93(2), 136.

Kahneman, D., \& Tversky, A. (1979). Prospect theory: An analysis of decision under risk. Econometrica: Journal of the econometric society, 263-291.

Karasek, R. A. (1979). Job Demands, Job Decision Latitude, and Mental Strain: Implications for Job Redesign. Administrative Science Quarterly, 24(2), 285-308.

Karr-Wisniewski, P., \& Lu, Y. (2010). When more is too much: Operationalizing technology overload and exploring its impact on knowledge worker productivity. Computers in Human Behavior, 26(5), 1061-1072. 
Klein, G., Jiang, J. J., \& Cheney, P. (2009). Resolving Difference Score Issues in Information Systems Research. MIS Quarterly, 33(4), 811-826.

Kristof-Brown, A. L., Zimmerman, R. D., \& Johnson, E. C. (2005). Consequences of Individuals' Fit at Work: A Meta-Analysis of Person-Job, Person-Organization, PersonGroup, and Person-Supervisor Fit. Personnel Psychology, 58(2), 281-342.

Lazarus, R. S. (1990). Theory-Based Stress Measurement. Psychological Inquiry, 1(1), 313.

Lazarus, R. S., \& Folkman, S. (1984). Stress, appraisal, and coping. New York, NY, USA: Springer publishing company.

Leiter, M. P., \& Maslach, C. (1988). The Impact of Interpersonal Environment on Burnout and Organizational Commitment. Journal of Organizational Behavior, 9(4), 297.

Levine, J. M., Samet, M. G., \& Brahlek, R. E. (1975). Information Seeking with Limitations on Available Information and Resources. Human Factors, 17(5), 502-513.

Lowry, P. B., D'Arcy, J., Hammer, B., \& Moody, G. D. (2016). "Cargo Cult" science in traditional organization and information systems survey research: A case for using nontraditional methods of data collection, including Mechanical Turk and online panels. The Journal of Strategic Information Systems, 25(3), 232-240.

Lyne, K. D., Barrett, P. T., Williams, C., \& Coaley, K. (2000). A psychometric evaluation of the Occupational Stress Indicator. Journal of Occupational \& Organizational Psychology, 73(2), 195-220.

Malhotra, N. K., Kim, S. S., \& Patil, A. (2006). Common Method Variance in IS Research: A Comparison of Alternative Approaches and a Reanalysis of Past Research. Management Science, 52(12), 1865-1883. 
Mano, R. S., \& Mesch, G. S. (2010). E-mail characteristics, work performance and distress. Computers in Human Behavior, 26(1), 61-69.

Mazmanian, M., Orlikowski, W. J., \& Yates, J. (2005). Crackberries: The social implications of ubiquitous wireless e-mail devices. In C. Sørensen, Y. Yoo, K. Lyytinen, \& J. DeGross (Eds.), Designing ubiquitous information environments: Socio-technical issues and challenges (pp. 337-343). New York: Springer.

McGrath, J. E. (1970). Social and psychological factors in stress (Vol. xi). New York: Holt, Rinehart and Winston, Inc.

McGrath, J. E. (1976). Stress and behavior in organizations. In M. D. Dunnette (Ed.), Handbook of industrial and organizational psychology. Chicago: Rand McNally.

Mikal, J. P., Rice, R. E., Abeyta, A., \& DeVilbiss, J. (2013). Transition, stress and computermediated social support. Computers in Human Behavior, 29(5), A40-A53.

Nunnally, J. (1978). Psychometric Theory. New York: McGraw-Hill.

O'Reilly, C. A. (1980). Individuals and Information Overload in Organizations: Is More Necessarily Better? Academy of Management Journal, 23(4), 684-696.

Park, Y., Fritz, C., \& Jex, S. M. (2015). Daily Cyber Incivility and Distress The Moderating Roles of Resources at Work and Home. Journal of Management, 1-23.

Pennington, R. R., \& Kelton, A. S. (2016). How much is enough? An investigation of nonprofessional investors information search and stopping rule use. International Journal of Accounting Information Systems, 21, 47-62.

Pew Research Center. (2014). Technology's Impact on Workers. Washington, D.C.

Pillet, J.-C., \& Carillo, K. D. A. (2016). Email-free collaboration: An exploratory study on the formation of new work habits among knowledge workers. International Journal of Information Management, 36(1), 113-125. 
Podsakoff, P. M., MacKenzie, S. B., Lee, J.-Y., \& Podsakoff, N. P. (2003). Common method biases in behavioral research: a critical review of the literature and recommended remedies. Journal of applied psychology, 88(5), 879.

Reinke, K., \& Chamorro-Premuzic, T. (2014). When email use gets out of control: Understanding the relationship between personality and email overload and their impact on burnout and work engagement. Computers in Human Behavior, 36, 502-509.

Renaud, K., Ramsay, J., \& Hair, M. (2006). "You've Got E-Mail!” ... Shall I Deal With It Now? Electronic Mail From the Recipient's Perspective. International Journal of Human-Computer Interaction, 21(3), 313-332.

Schank, R. C., \& Abelson, R. (1977). Scripts, goals, plans, and understanding. Hillsdale, NJ: Erlbaum.

Schultz, U., \& Vandenbosch, B. (1998). Information Overload in a Groupware Environment: Now You See It, Now You Don't. Journal of Organizational Computing and Electronic Commerce, 8(2), 127-148.

Selye, H. (1956). The stress of life. New York, NY, USA: McGraw-Hill.

Smith, W. P., \& Tabak, F. (2009). Monitoring Employee E-mails: Is There Any Room for Privacy? Academy of Management Perspectives, 23(4), 33-48.

Soucek, R., \& Moser, K. (2010). Coping with information overload in email communication: Evaluation of a training intervention. Computers in Human Behavior, 26(6), 1458-1466.

Sumecki, D., Chipulu, M., \& Ojiako, U. (2011). Email overload: Exploring the moderating role of the perception of email as a 'business critical' tool. International Journal of Information Management, 31(5), 407-414.

Sutherland, V. J., \& Cooper, C. L. (2000). Strategic stress management: An organizational approach. Palgrave Macmillan. 
Tarafdar, M., Cooper, C. L., \& Stich, J.-F. (2017). The technostress trifecta - techno eustress, techno distress and design: An agenda for research. Information Systems Journal, doi:10.1111/isj.12169.

Tarafdar, M., D'Arcy, J., Turel, O., \& Gupta, A. (2015). The Dark Side of Information Technology. Sloan Management Review, 56(2), 60-71.

Tarafdar, M., Qiang Tu, Ragu-Nathan, B. S., \& Ragu-Nathan, T. S. (2007). The Impact of Technostress on Role Stress and Productivity. Journal of Management Information Systems, 24(1), 301-328.

Tversky, A., \& Kahneman, D. (1978). Causal schemas in judgments under uncertainty. In M. Fishbein (Ed.), Progress in Social Psychology (Vol. 1). Hillsdale, NJ: Erlbaum.

Van Harrison, R. (1978). Person-environment fit and job stress. In C. L. Cooper \& R. Payne (Eds.), Stress at work (pp. 175-205). Wiley.

Wajcman, J., \& Rose, E. (2011). Constant Connectivity: Rethinking Interruptions at Work. Organization Studies, 32(7), 941-961.

Waller, A. D., \& Ragsdell, G. (2012). The impact of e-mail on work-life balance. Aslib Proceedings, 64(2), 154-177.

Wetzels, M., Odekerken-Schröder, G., \& Van Oppen, C. (2009). Using PLS path modeling for assessing hierarchical construct models: Guidelines and empirical illustration. MIS quarterly, 177-195.

Whittaker, S., \& Sidner, C. (1996). Email Overload: Exploring Personal Information Management of Email. In Proceedings of the SIGCHI Conference on Human Factors in Computing Systems (pp. 276-283). New York, NY, USA: ACM.

Williams, C. (2011, December 23). WW to switch off BlackBerry servers outside work hours. The Telegraph. 


\section{Appendix}

\begin{tabular}{|c|c|c|}
\hline & $\begin{array}{l}\text { Percentage } \\
\text { Sample }\end{array}$ & $\begin{array}{c}\text { Percentage } \\
\text { US } \\
\text { population }\end{array}$ \\
\hline \multicolumn{3}{|l|}{ Sex } \\
\hline Male & $36 \%$ & $53 \%$ \\
\hline Female & $64 \%$ & $47 \%$ \\
\hline Total & $100 \%$ & $100 \%$ \\
\hline \multicolumn{3}{|c|}{ Industry (North American Industry Classification System - NAICS) } \\
\hline Agriculture, forestry, fishing, and hunting & $0 \%$ & $1 \%$ \\
\hline Mining, quarrying, and oil and gas extraction & $2 \%$ & $1 \%$ \\
\hline Construction & $3 \%$ & $6 \%$ \\
\hline Manufacturing & $9 \%$ & $10 \%$ \\
\hline Wholesale and retail trade & $3 \%$ & $14 \%$ \\
\hline Transportation and utilities & $4 \%$ & $5 \%$ \\
\hline $\begin{array}{l}\text { Information services (broadcasting, telecommunications, } \\
\text { data hosting etc.) }\end{array}$ & $7 \%$ & $2 \%$ \\
\hline Financial services & $13 \%$ & $7 \%$ \\
\hline Professional and business services & $20 \%$ & $12 \%$ \\
\hline Education and health services & $11 \%$ & $23 \%$ \\
\hline Leisure and hospitality & $5 \%$ & $9 \%$ \\
\hline Other services & $19 \%$ & $5 \%$ \\
\hline Public administration & $5 \%$ & $5 \%$ \\
\hline Total & $100 \%$ & $100 \%$ \\
\hline
\end{tabular}


The paper develops and tests theory that explains under what conditions the extent of email use is appraised as a stressor. Integrating concepts from information acquisition and person environment fit theories, we theorize that individuals appraise their extent of email use as stressful based on the mismatch between their current and desired extents of email use. We define such match as email fit and mismatch as email misfit. We develop a conceptual framework and hypotheses that associates email misfit with the individual's experience of three key workplace stressors - work relationship stressor, job control stressor and job conditions stressor. We test our hypotheses by applying quadratic polynomial regressions and surface-response analysis, to survey data obtained from 118 working individuals. The paper makes three theoretical contributions. Firstly, in reporting a theoretical and empirical construction of email fit and misfit and their relationship to workplace stressors, it shows that, email misfit is appraised as stress-creating. That is, both too much and too little email compared to what the individual desires, are associated with stressors. In doing so and secondly, it shows that IT use (in this case, email) is appraised as stressful both when it exceeds (i.e., associated with overload) and fails to meet (i.e., associated with underload), the user's expectation and preference. Thirdly, it suggests the person environment approach as a theoretically novel way to conceptualize the cognitive appraisal and judgement associated with information under - and over - acquisition, and shows workplace stressors as potentially new effects associated with the 